AEC RESEARCH AND DEVELOPMENT REPORT

\title{
A COMPUTER PROGRAM FOR CIRCULATION OF LIBRARY JOURNALS
}

\author{
M. W. Skelton \\ R. R. Haefner
}

SRL

RECORO COPY

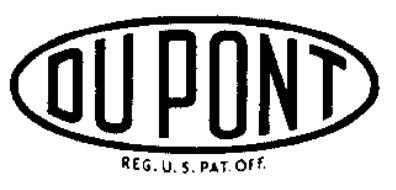

Savannah River Laboratory

Aiken, South Carolina 


\section{LEGAL NOTICE}

This report was prepared as an account of Government sponsored work. Neither the United States, nor the Commission, nor any person acting on behalf of the Commission:

A. Makes any warranty or representation, expressed or implied, with respect to the accuracy, completeness, or usefulness of the information contained in this report, or that the use of any information, apparatus, method, or process disclosed in this report may not infringe privately owned rights; or

B. Assumes any liabilities with respect to the use of, or for damages resulting from the use of any information, apparatus, method, or process disclosed in this report.

As used in the above, "person acting on behalf of the Commission" includes any employee or contractor of the Commisaion, or employee of such contractor, to the extent that such employee or contractor of the Commission, or employee of such contractor prepares, disseminates, or provides access to, any information pursuant to his employment or contract with the Commission, or his employment with such contractor.

Printed in USA. Price $\$ 3.00$

Avallable from the Clearinghouse for Federal Scientif $1 \mathrm{c}$

and Technical Information, National Bureau of Standards,

U. S. Department of Commerce, Springfield, Virginia 


$$
664316
$$

Mathematics and Computers

(TID-4500, 4lst Ed.)

\title{
A COMPUTER PROGRAM FOR CIRCULATION
}

OF LIBRARY JOURNALS

\author{
by \\ Margaret W. Skelton \\ and \\ Richard R. Haefner
}

Approved by

J. W. Wade, Research Manager

Applied Mathematics Division

June 1965

E. 1. DU PONT DE NEMOURS \& COMPANY

SAVANNAH RIVER LABORATORY

AIKEN, SOUTH CAROLINA

CONTRACT AT(07-2).1 WITH THE

UNITED STATES ATOMIC ENERGY COMMISSION 


\begin{abstract}
A computer program, JURN, has been written in FORTRAN II which automates the repetitive paperwork needed to circulate technical journals. The program reduces to a minimum the time and effort required to prepare and maintain current records.

The program provides printed distribution slips for each circulating journal, notification of reorder dates, listings of circulating and reference journals, and complete listings of library holdings.

A maximum of 1000 people and 750 separate journals (titles) can be accommodated by this program. Up to 50 coples of each journal may be circulated to a maximum of 16 people per copy.
\end{abstract}


Introduction

Structure of the Program 5

$\begin{array}{ll}\text { Capabilities of the Program } & 10\end{array}$

$\begin{array}{ll}\text { Input } & 10\end{array}$

Original Input $\quad 10$

$\begin{array}{ll}\text { Updating Input } & 14\end{array}$

Sample Output 22

Handling Procedures and Operating Instructions 30

FORTRAN II Listing of the Program 31

\section{LIST OF FIGURES}

\section{Figure}

1 Flowsheet for the JURN Program 6

$\begin{array}{lll}2 & \text { Flowsheet for Subroutine CHANGE } & 7\end{array}$

3 Flowsheet for Subroutine TAPMAK 8

4 Flowsheet for Subroutine PERSTP 9 
$-4-$ 


\section{A COMPUTER PROGRAM FOR CIRCULATION OF LIBRARY JOURNALS}

\section{INTRODUCTION}

The library of the Savannah River Laboratory currently receives and circulates $\sim 500$ periodicals to $\sim 600$ Plant and Laboratory personnel. It was desirable to develop a computer program that could perform much of the clerical work. The following tasks that were performed by the library staff are amenable to automation: (1) maintenance of an up-to-date list of available periodicals and the circulation list for each periodical, (2) printing of circulation slips, and (3) notification of renewal dates.

\section{STRUCTURE OF THE PROGRAM}

The program includes a main program and elght subroutines (Figure 1 ). Five of the subroutines that deal directly with the output are easily understood and do not require detailed explanation.

The input is arranged in two blocks: (1) the people who recelve the journals periodically - name, payroll number, and location; (2) the journals - titles, general information, and distribution lists composed of the payroll number of each person to whom this periodical is circulated.

The most important functions deal with updating the input tape and converting the input to a form more easily used for the library tape. These operations are performed by the three subroutines described below.

The first, subroutine CHANGE (Figure 2), updates the existing library tape. The procedure accommodates changes in (1) the list of people who receive journals, (2) journal titles, (3) general information, and (4) distribution lists. A new input tape is generated by combining the designated changes and the old tape.

The new input tape is the basis for the library tape. Two subroutines, TAPMAK (Figure 3) and PERSTP (Figure 4), are required to generate four blocks of information on the library tape. The flrst block on the tape is a list of each person's name. The second block is a group of $\mathrm{X}$ records, where $X$ is the total number of fournals. Each record is associated with one journal and consists of the title, general information, and distribution lists for that journal. The third block is an alphabetic list of the name of each journal.

The fourth block of information is developed by the PERSTP subroutine. This subroutine rearranges the above three blocks of information to form a block of $Y$ records, where $Y$ is the number of people who receive these journals. Each record represents one person and contains the person's name and the index number of each journal that he receives. 


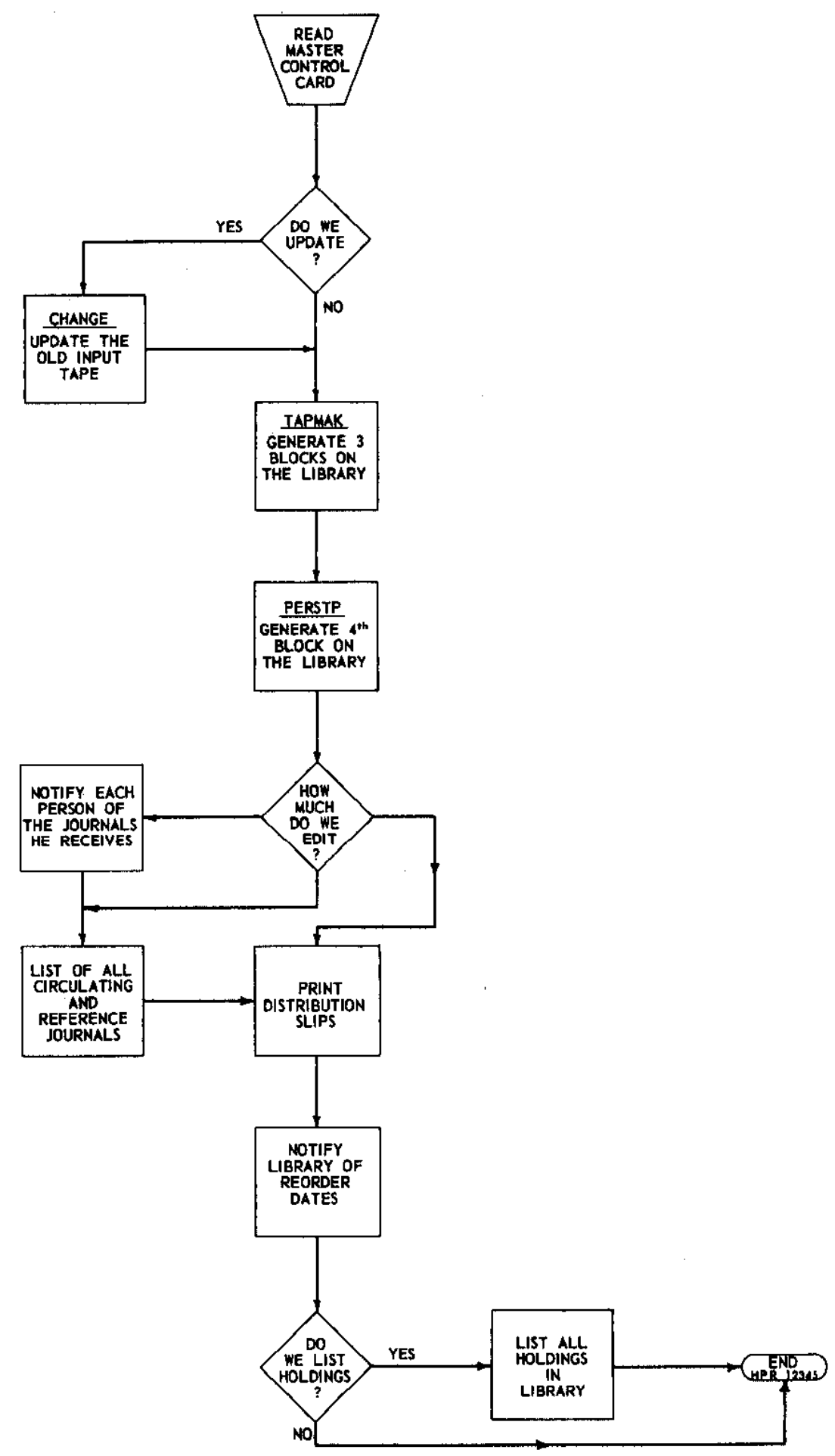

FIG. I FLOWSHEET FOR THE JURN PROGRAM 


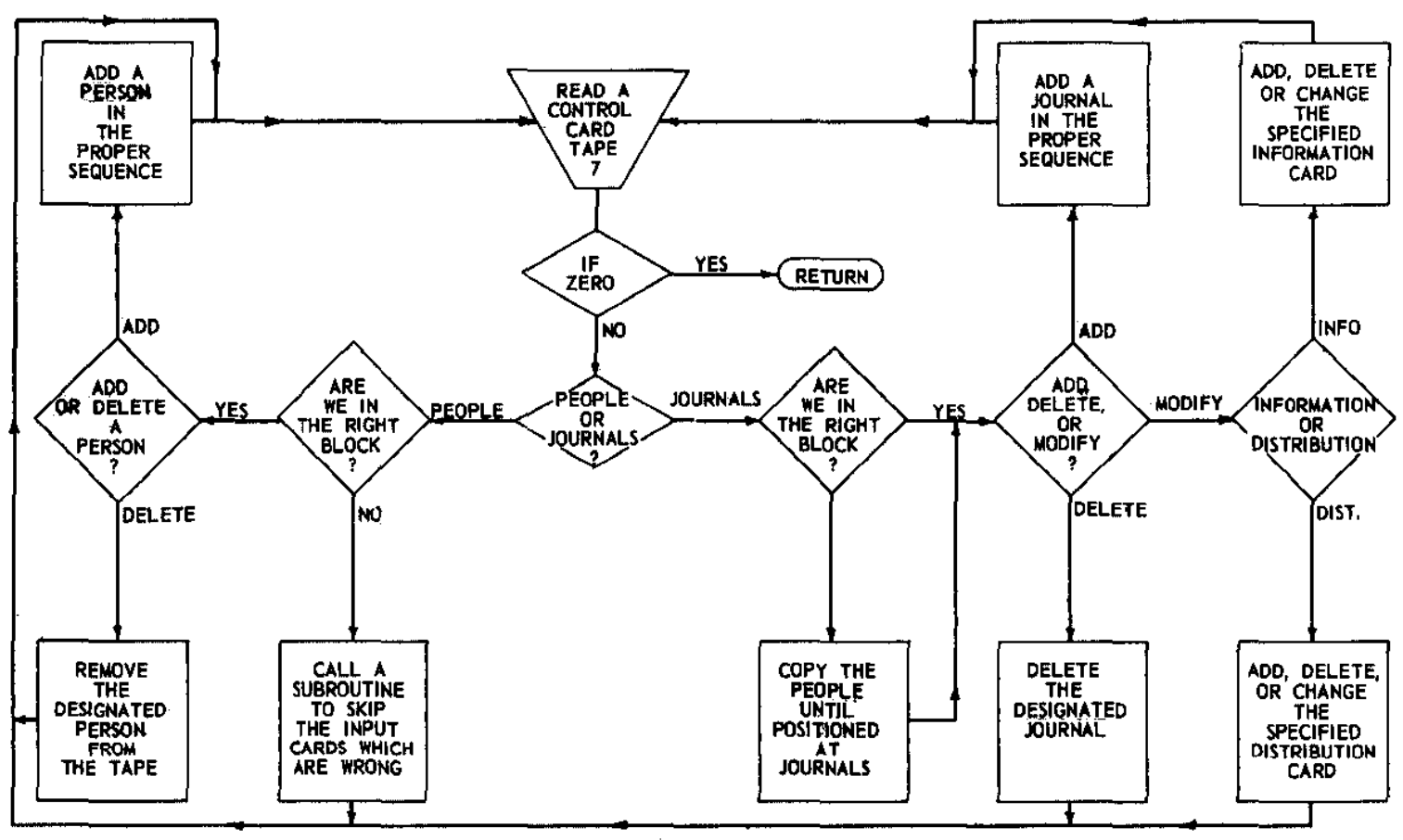

*NOTES FOR MODIFICATIONS

The progrom will:

1. Find the specified journal.

2. Find the specified cord.

3. Insert an oddition of the proper place.

4. Read over an item without copying for a doletion.

5. Read over on item, correct, and copy the corrected item for a chengo.

6. Read next control card.

7. Make subsequent chonges to the some journal.
8. Copy to and of joumal.

9. Allow foumals to be added at and of tope.

10. Copy the master tope if the chonges

FIG. 2 FLOWSHEET FOR SUBROUTINE CHANGE 


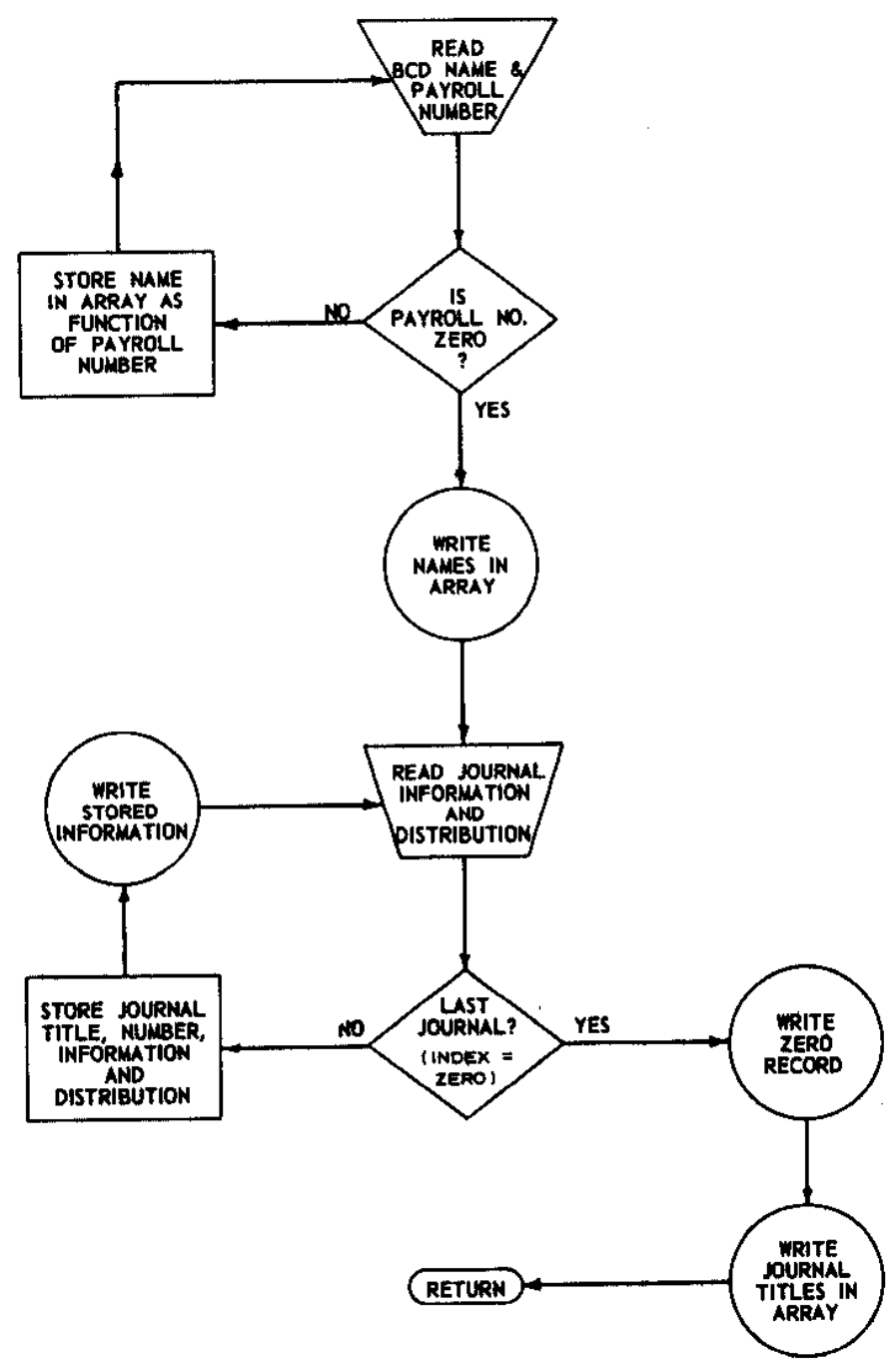

FIG. 3 FLOWSHEET FOR SUBROUTINE TAPMAK 


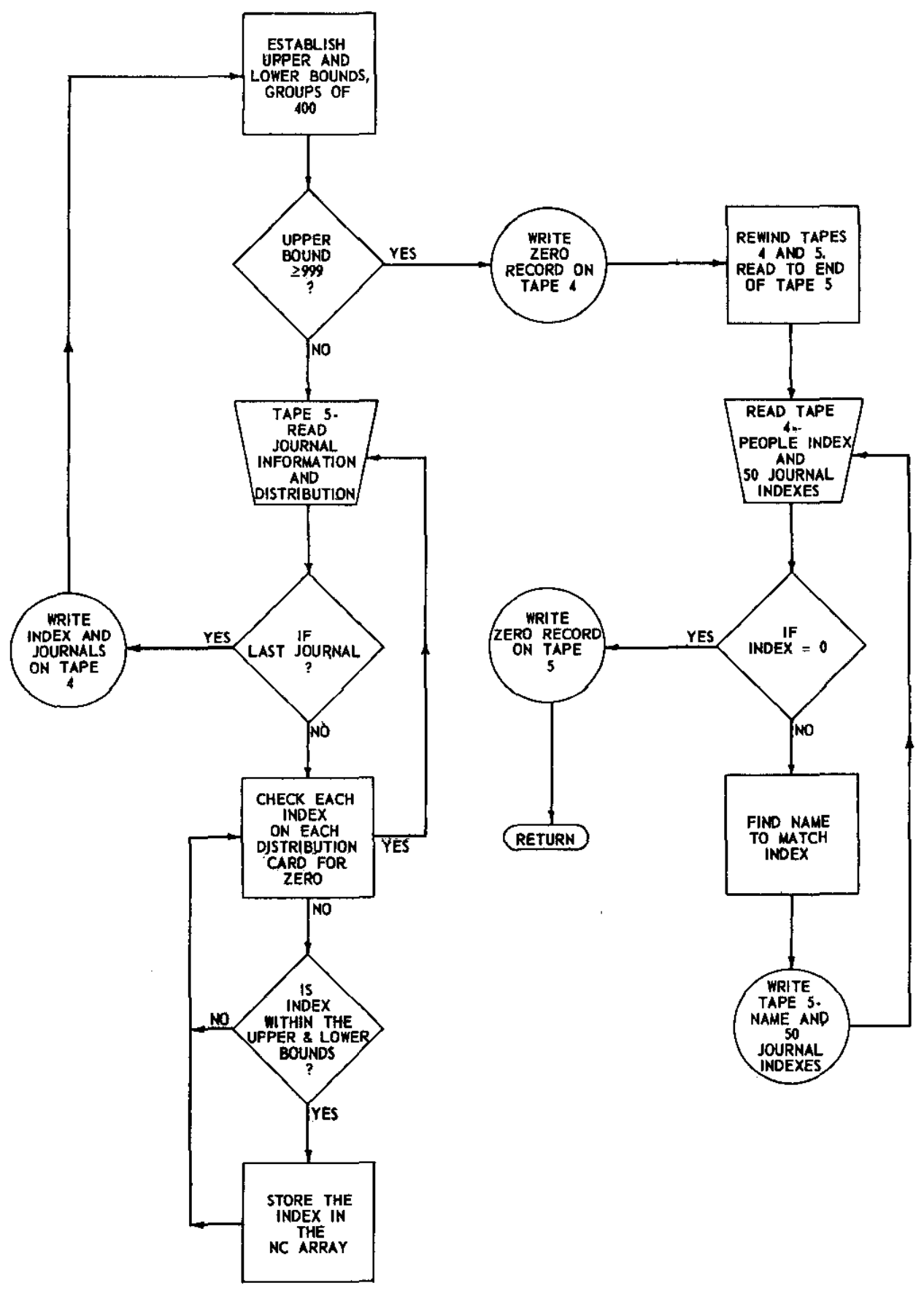

FIG. 4 FLOWSHEET FOR SUBROUTINE PERSTP 


\section{CAPABILITIES OF THE PROGRAM}

There are several limiting factors in this program. The maximum number of people who can be accommodated is 999 . The index number for each person is his payroll number. Each name and location is allowed 18 alphanumeric characters which require 3 storages in computer memory. The program can accommodate 750 periodicals. The index number for each journal is unique and random, but cannot exceed the number 750 . The name of the journal is allowed 24 alphanumeric characters which require 4 storages in computer memory.

There are a maximum of 8 information cards for each journal. Each distribution card represents one copy of that journal. Each copy can be circulated to a maximum of 16 people. There can be up to 30 regular distribution cards and up to 20 departmental distribution cards for each journal.

On the sample problem, execution time was 35 minutes on a $32 \mathrm{~K}$ IBM 704 with model 727-III tape units. The problem consisted of (1) making 15-20 changes to an input tape containing 580 people and 130 journals, and (2) obtaining all possible output from the program. Due to the necessary manipulation of tapes, the execution time will increase as the tapes get longer.

The estimated maximum run time for 999 people and 750 journals may be approximately 2 hours.

\section{INPUT}

\section{Original Inpu†}

There are two types of cards for the original input tape: the "Journal cards" and the "people cards".

For each periodical there are 4 categories of journal cards designated as (1) "periodical card", (2) "direct order card", (3) "information cards", and (4) "distribution cards".

$\begin{array}{rcl}\text { The "people cards" } & \text { contain in } \\ \text { Columns } & 1-4 & \text { Payroll number } \\ 5-10 & \text { Blank } \\ 11-24 & \text { Name of person } \\ & \\ & & \text { Location }\end{array}$


EXAMPLE: "People Card" ( 1 per person)
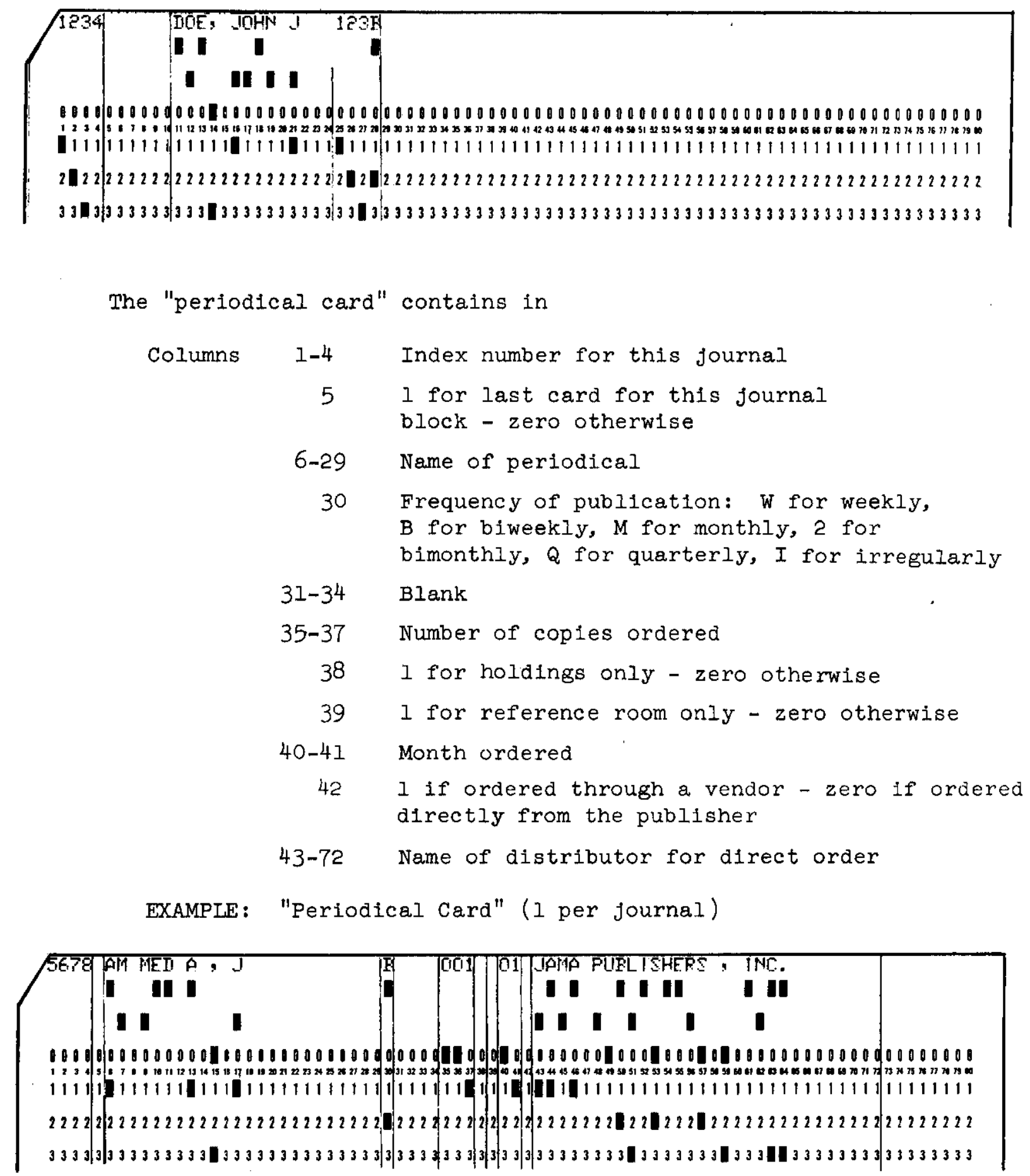
The "airect order card" contains in

$$
\text { Columns } \begin{aligned}
1-4 & \text { Index number for this journal } \\
5 & \begin{array}{l}
\text { 1 for last card for this journal } \\
\text { block - zero otherwise }
\end{array} \\
6-35 & \text { Street address (for distributor) } \\
36-65 & \text { City and state }
\end{aligned}
$$

EXAMPLE: "Direct Order Card" ( 1 per journal if column 42 in periodical card is zero or blank. If column $42=1$, this card is not necessary.)

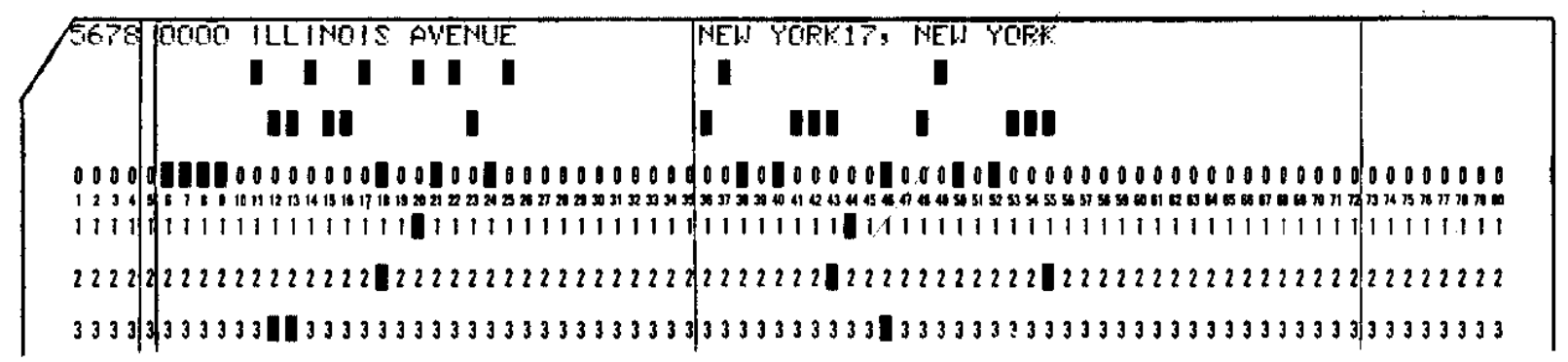

The "information cards" contain in

Columns I-4 Index number for this journal

5 I for last card for this journal

block - zero otherwise

6-71 Alphabetic information

EXAMPLE: "Information Card" ( 6 per journal. The first should contain the full name of the periodical.)

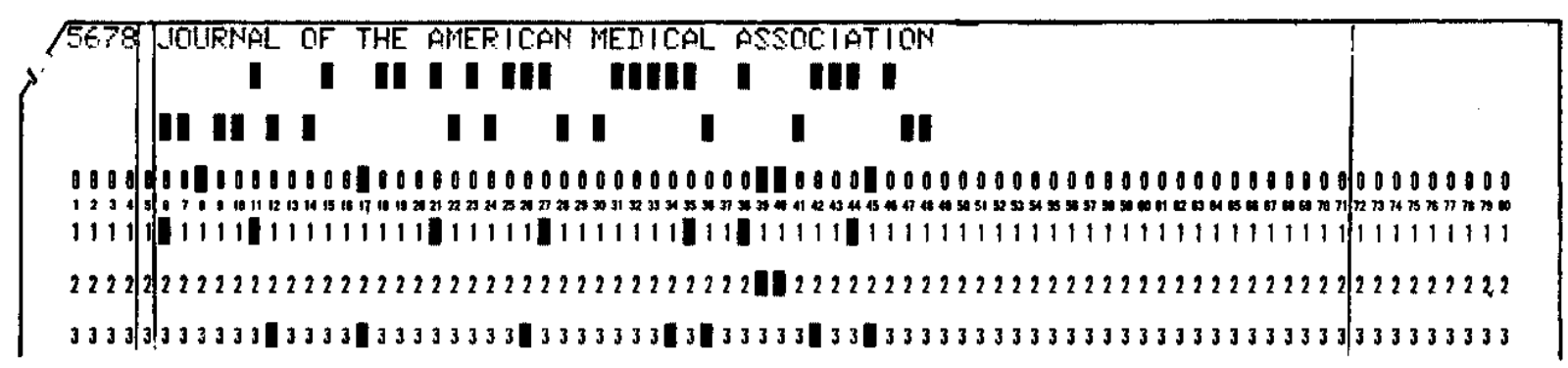


The "distribution cards" contain in

$\begin{aligned} & \text { Columns } \begin{aligned} \text { Index number for this journal } \\ 5\end{aligned} \\ & \begin{aligned} \text { l for last card for this journal } \\ \text { block - zero otherwise }\end{aligned} \\ & 6-7 \begin{array}{l}\text { Blank } \\ 8\end{array} \\ & 1 \text { for departmental copy - zero otherwise } \\ & 9-72 \begin{array}{l}16 \text { four-digit numbers corresponding to } \\ \text { distribution list }\end{array}\end{aligned}$

EXAMPLE: "Distribution Cards"

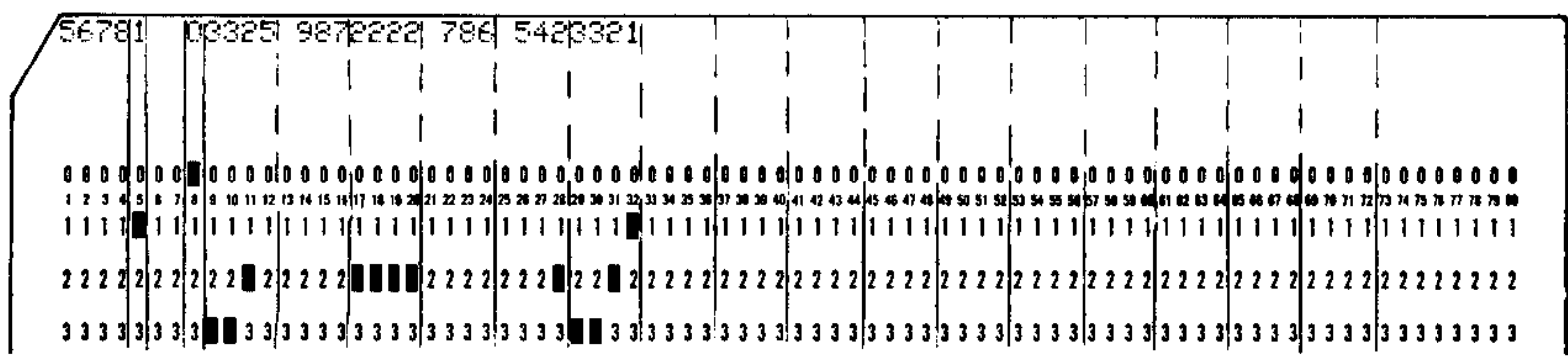

The cards are arranged for the master tape as follows:

1. "People Cards"

2. One blank card

3. "Journal Cards"

4. One blank card

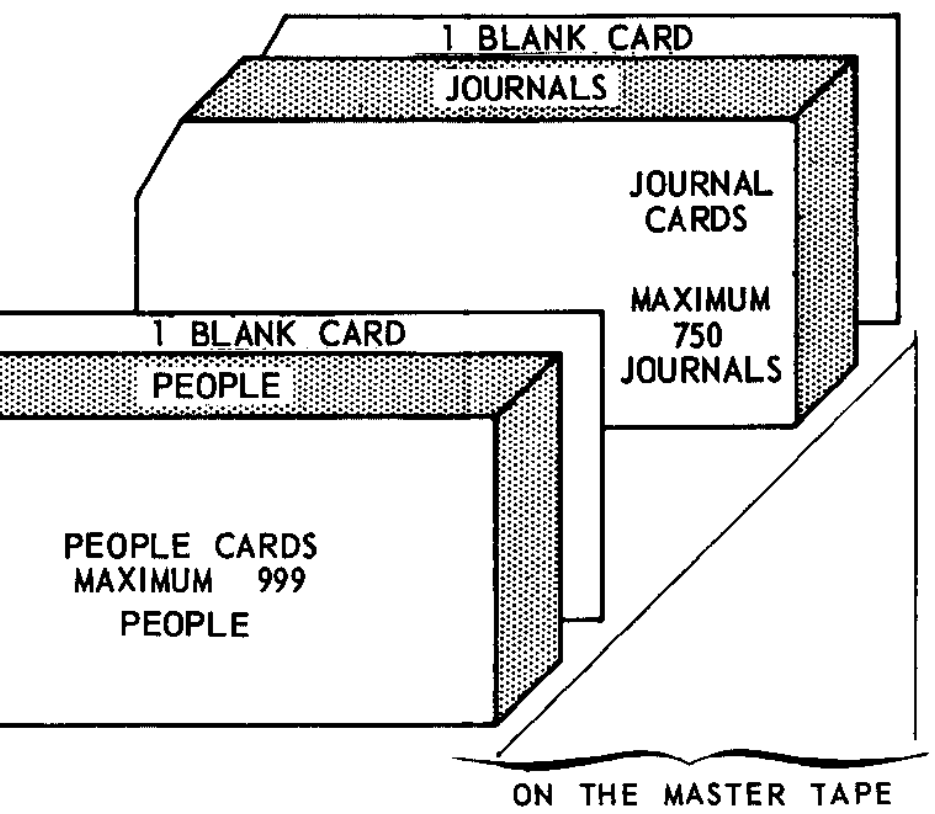




\section{Updating Input}

One master control card should be the first card of input immediately followed by the changes. If no changes are to be made, this will be the only input card. The control card should contain in
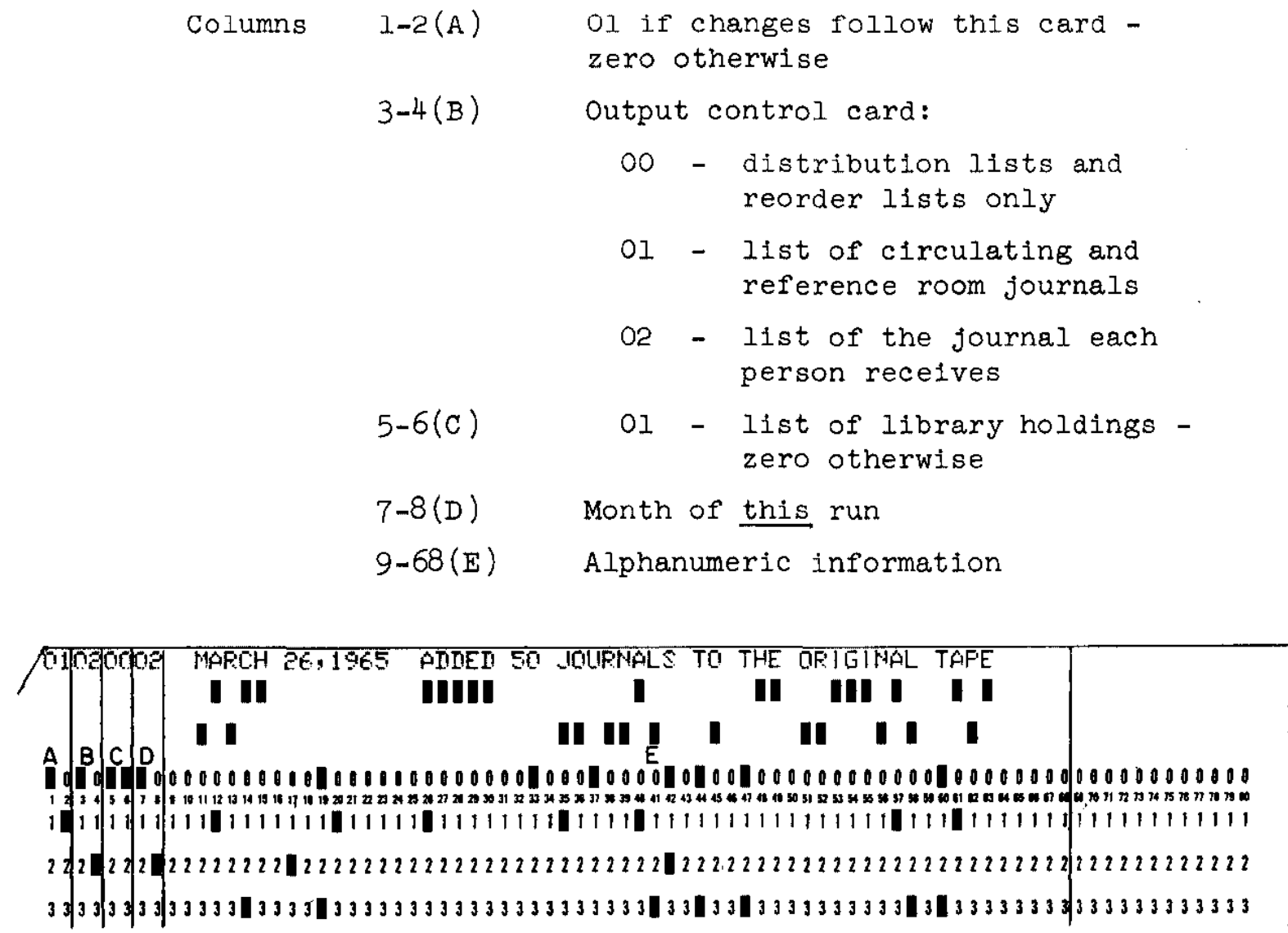

Nine procedures for updating input are available, each slightly different from the others.

1. Add a name to the circulation list (alphabetical order).

2. Delete a name from the circulation list.

3. Change a name, number, or location for someone already on the circulation list.

4. Add a journal (alphabetical order).

5. Delete a journal. 
6. Change a periodical card, a direct order card, or any of the 6 information cards.

7. Add an information card or a distribution card.

8. Delete an information or a distribution card.

9. Change a distribution card.

Each of the nine categories (Example) requires one control card. "Delete" processes (categories 2, 5, 8) require the control card only. Change processes (categories 6, 9) require the control card plus the corrected card for replacement. The procedure for adding people, information cards, or distribution cards (categories 1, 7)

control card plus the addition card. The changing of a name, location, or number for a person (category 3) requires two steps: (1) add the corrected card, (one control card plus the addition card); and (2) delete the old card (one control card only).

The addition of a journal (category 4) requires a control card plus the block of "journal cards" which belongs to that periodical. 


\title{
EXAMPLE
}

The nine possible control cards are shown in the following format.

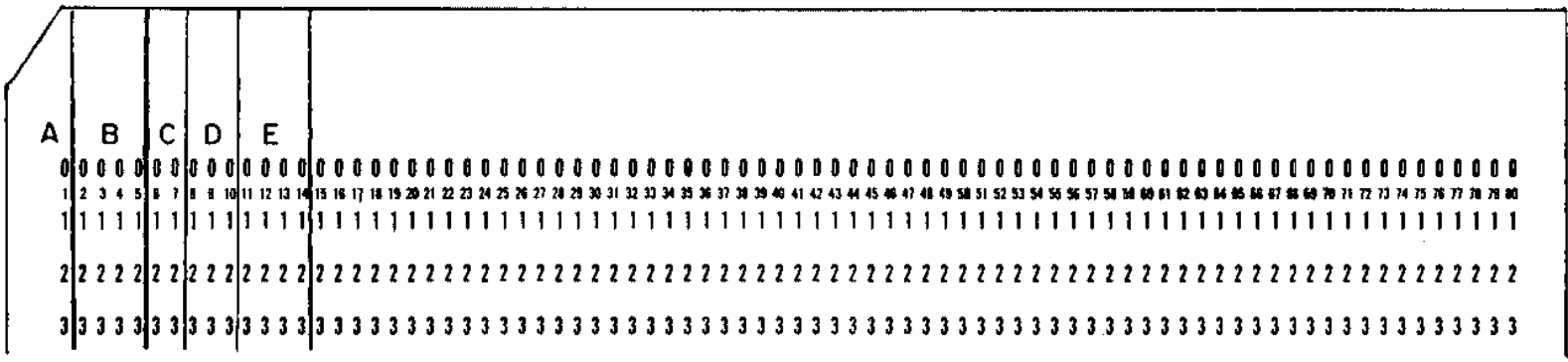

where: $A=I$ for updating people

2 for updating journals

$B=$ Index of object to be updated (person or journal index)

$C=$ Index of operations to be performed

OI - Insert a person

02 - Delete a person

03 - Insert a journal

04 - Delete a journal

05 - Change a "journal card" or add, delete, or change a distribution card

$D=$ Number of card which follows this control card (use $D$ for changes only)

\author{
001 - Periodical card \\ 002 - Direct order card \\ 003-008 - Information card \\ 901-950 - Distribution card \\ $E$ = Case $I$ - for additions of people or journal, $E$ = Index of the \\ person or journal this addition should follow \\ Case II - for change of any "journal" card, E = 0000 \\ Case III - for addition of a distribution card or an \\ information card, $E=0001$ \\ Case IV - for deletion of a distribution card or an \\ information card, $\mathrm{E}=0002$
}


The nine control cards are prepared according to the instructions on the preceding page.

1. Add a name to circulation list (2 cards)

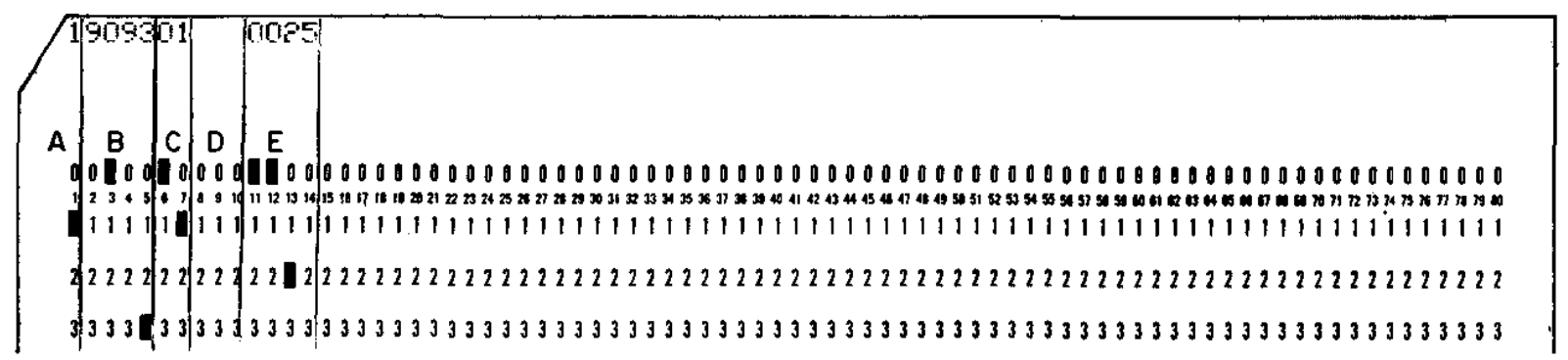

Control card

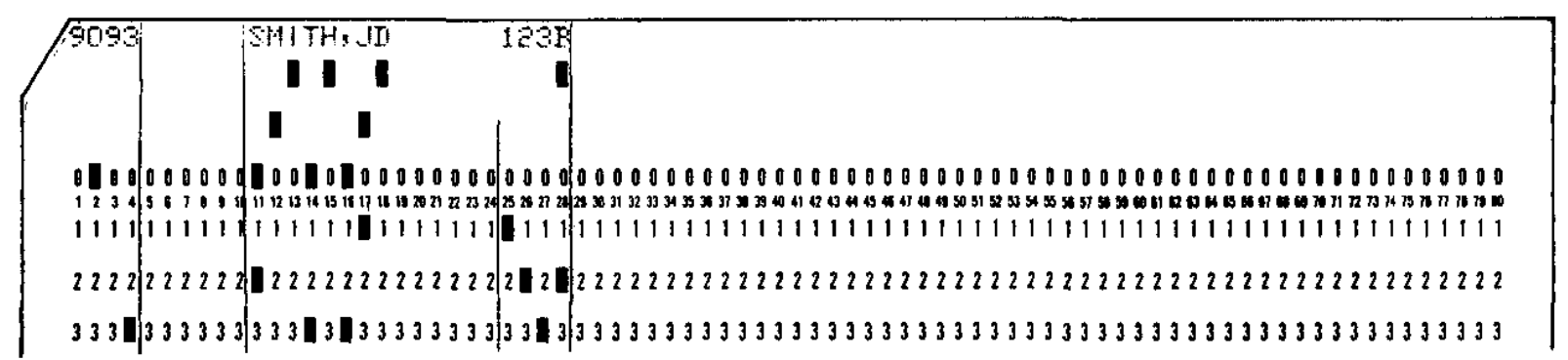

Addition card

2. Delete a name from circulation list (I card)

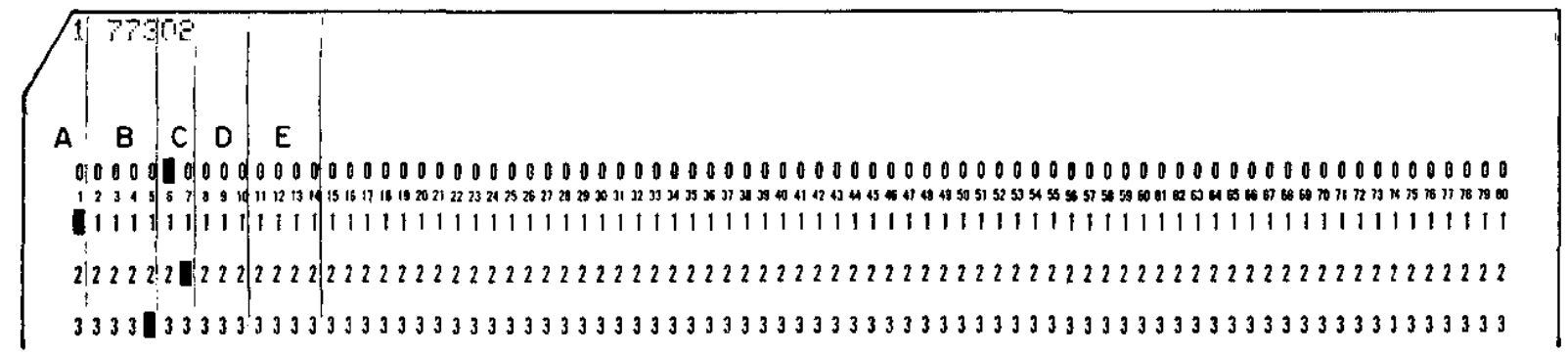

Control card 
3. Change a name, number, or location for someone already on the circulation

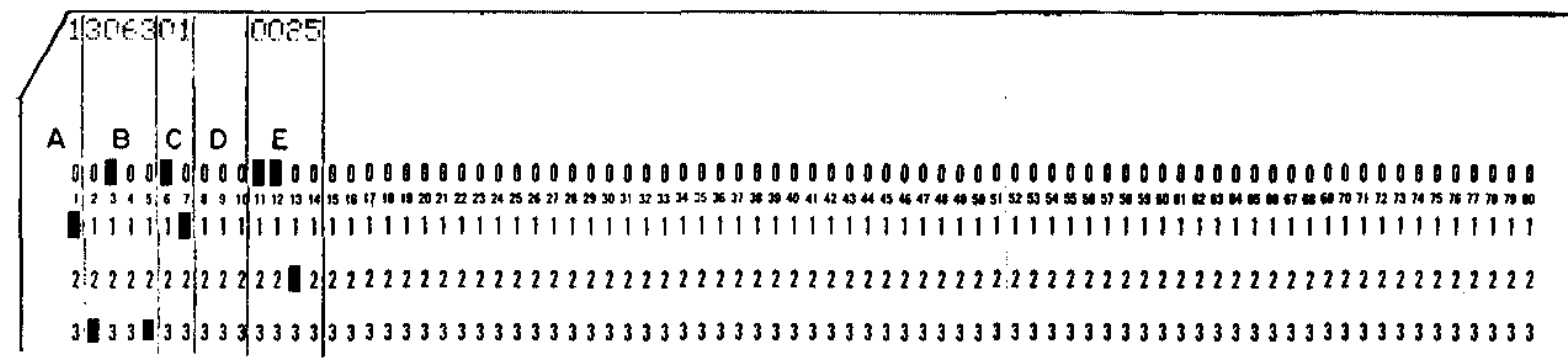

Control card

(insert correct card)

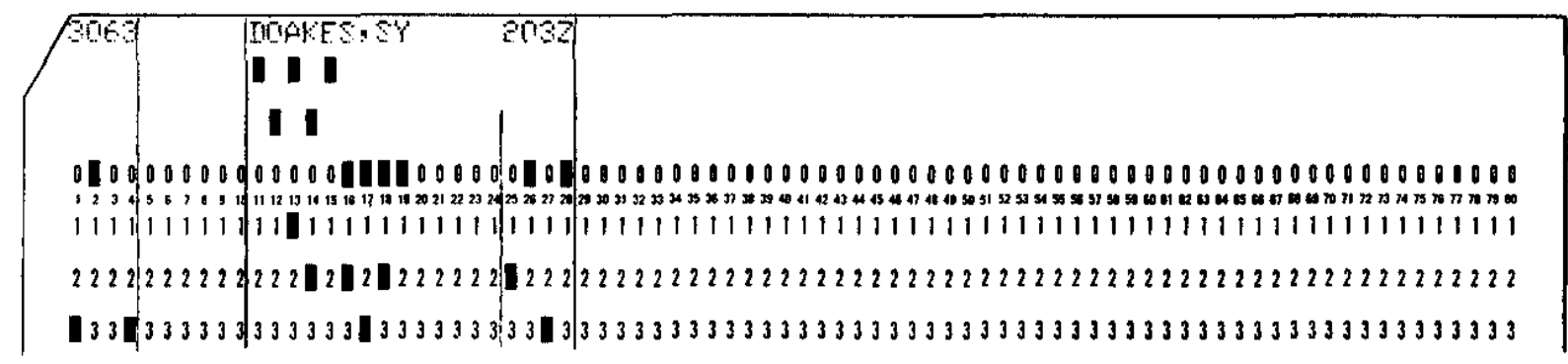

Step I Corrected card

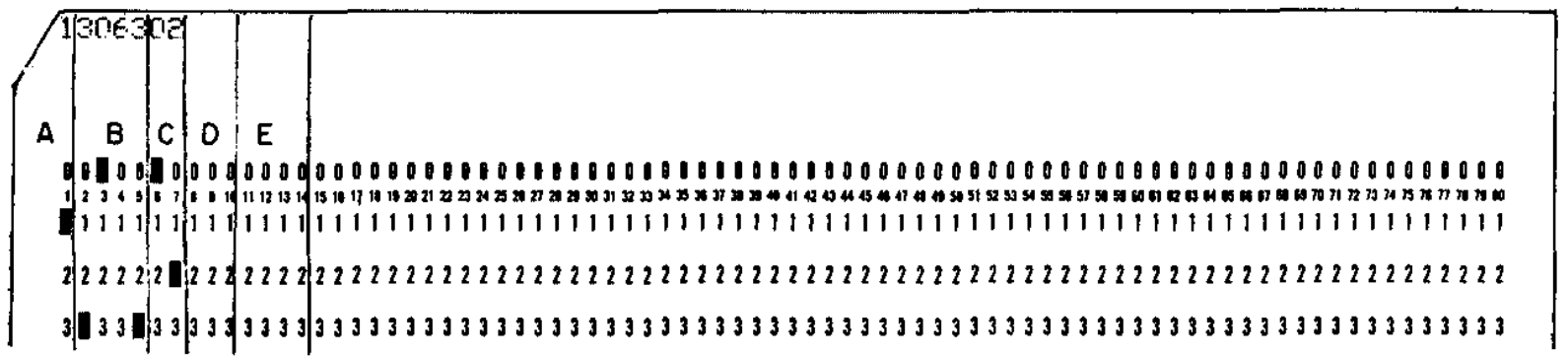

Step II

Control card

(delete the wrong card) 
4. Add a journal (I control card and "journal cards")

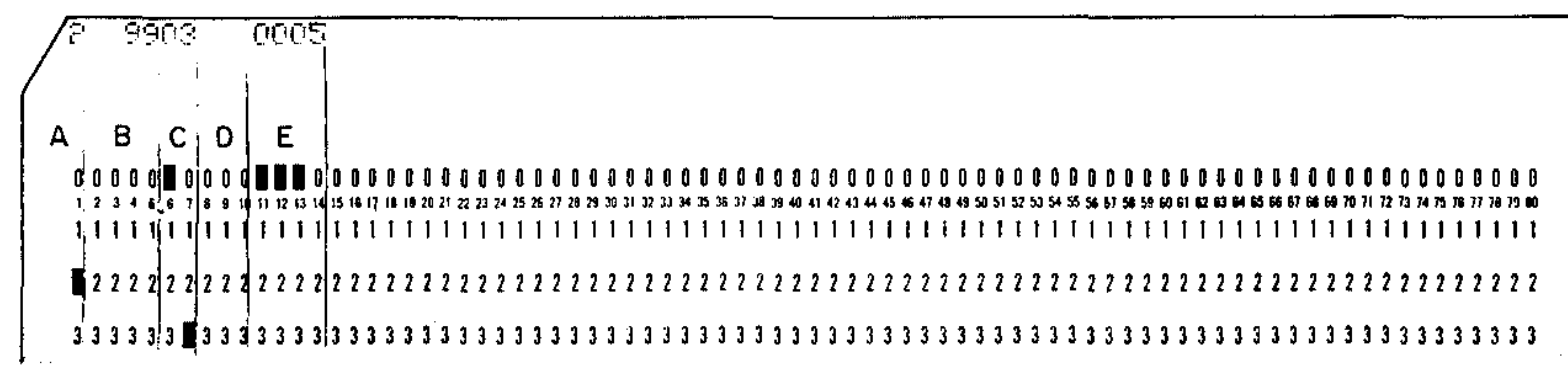

Control cara

"Journal" Cards - The control card must be followed by a periodical card, direct order card if necessary, 6 information cards, and the distribution cards for the new journal.

5. Delete a journal ( 1 card)

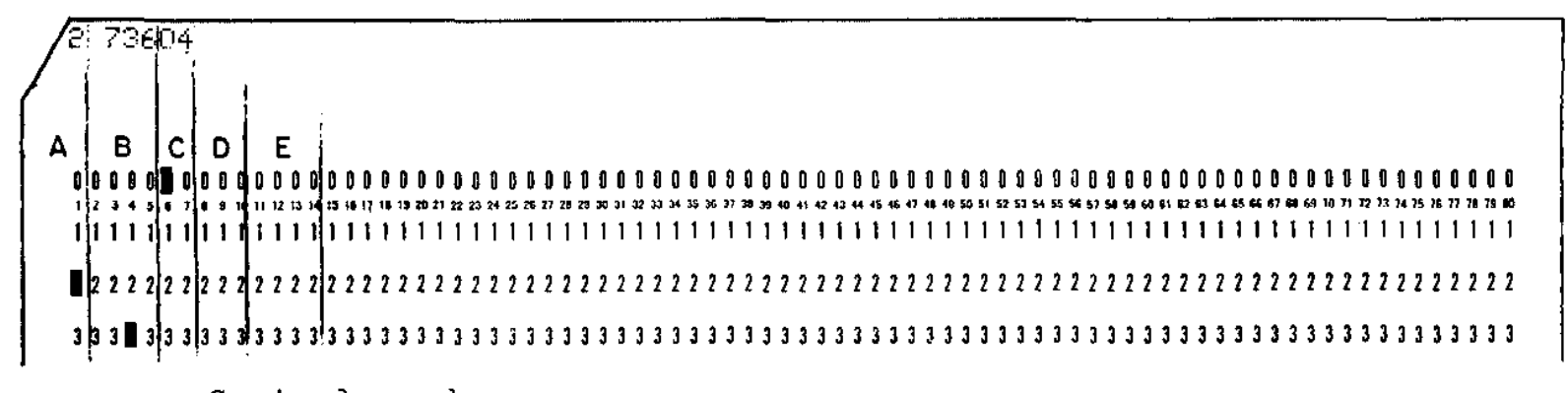

Control card 
6. Change a periodical card, a direct order card, or any of the 6 information cards (2 cards)

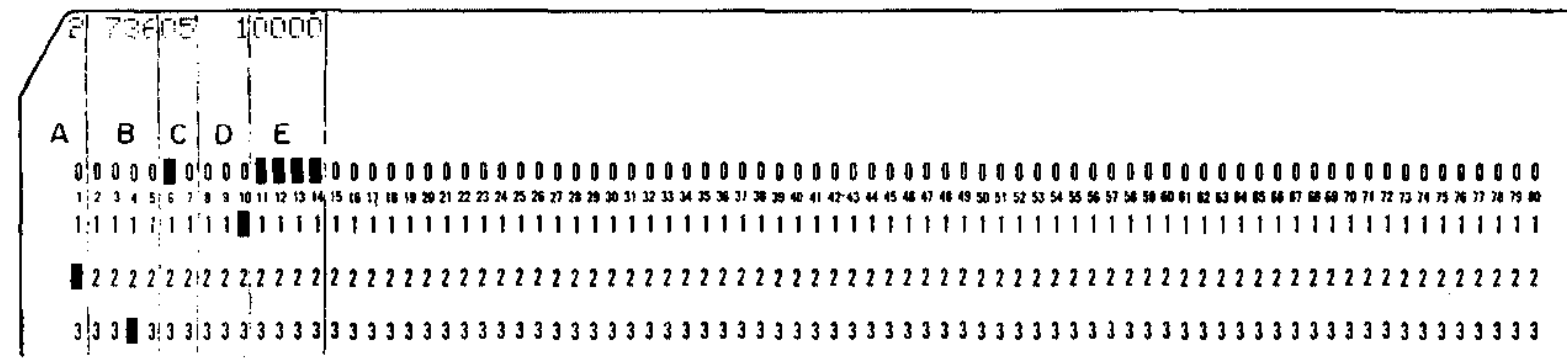

Control card

NOTE: See the list for $D$ for proper numbers to use.

Corrected Card - The corrected card must follow this control card, and it must be in the format described for the card corresponding to the number in $\mathrm{D}$.

7. Add a distribution or information card (2 cards)

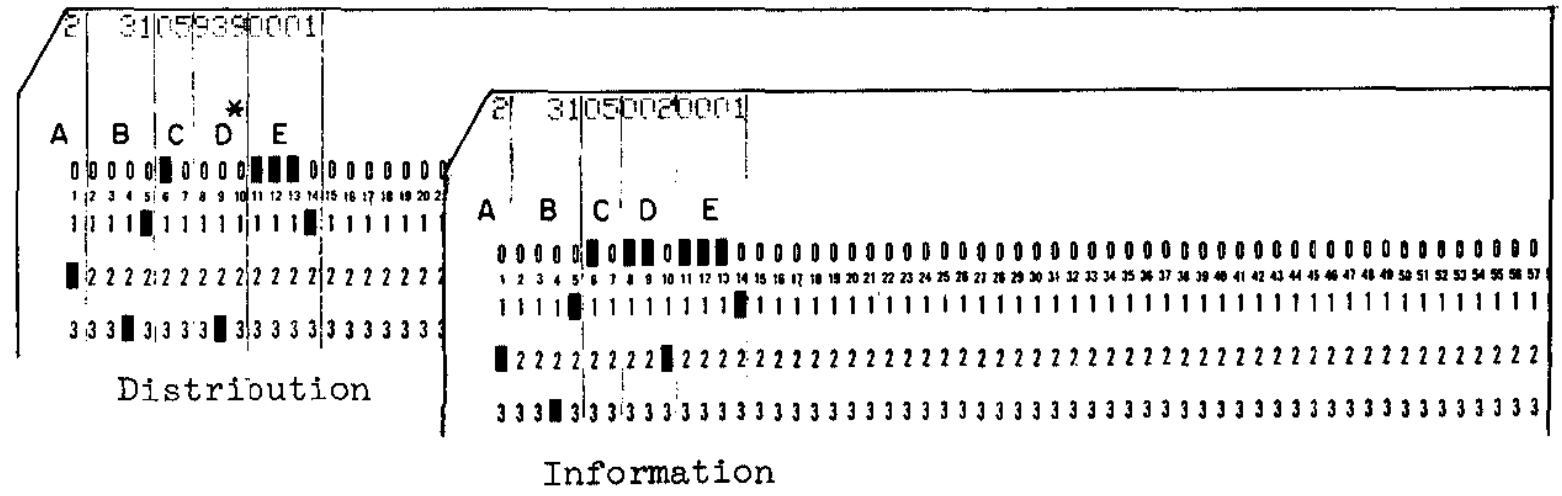

Control card

* NOTE: D must be 901 or greater to indicate that this is a distribution card - the number itself is of no interest and will not conflict with existing cards.

Card to be added follows here. 
8. Delete a distribution or information card ( 1 card only)

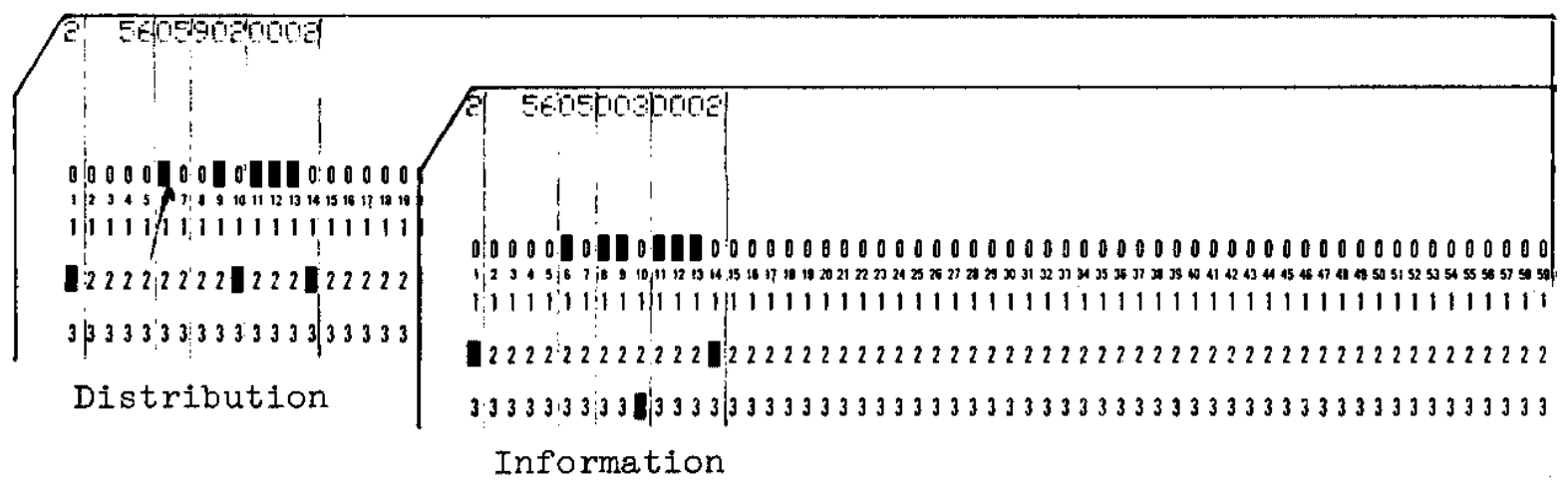

Control card

NOTE: The last distribution card must never be deleted. Only changes should be made to the last card.

9. Change a distribution card (2 cards)

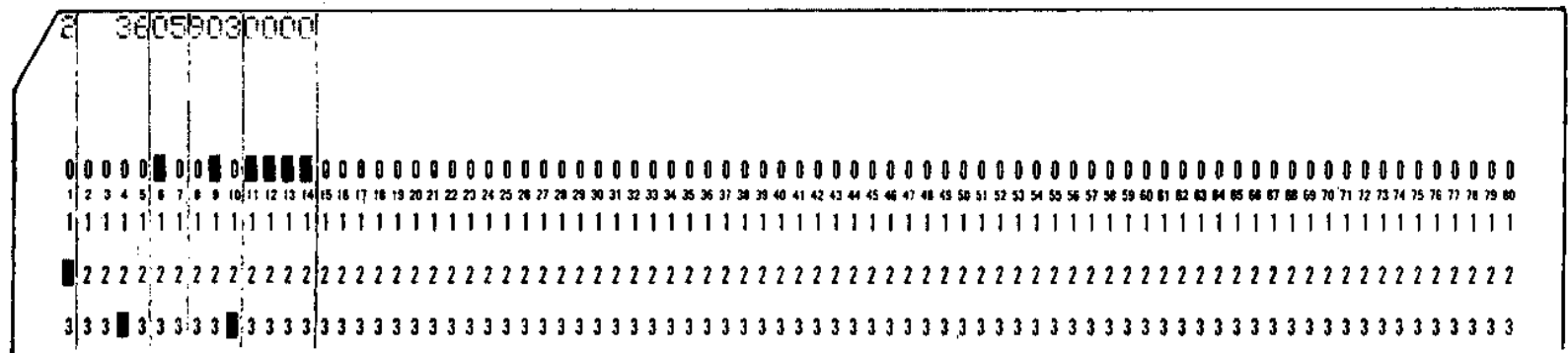

Control card

The corrected distribution card should follow this control card.

The following rules should be used in setting up the changes.

(I) The master control card must precede the changes.

(2) Change, add, or delete the circulation list first and in the same sequence as the tape.

(3) Change, add, or delete "Journal cards" in the same sequence as they appear on the tape.

(4) Within each journal block, make changes, additions, or deletions as they appear within the block. The prescribed order is: periodical card, direct order card, information cards, and distribution cards.

(5) The last card of the "change" input should be blank. 
SAMPLE OUTPUT

The distribution lists and the reorder lists are standard for each run. A distribution list is printed $X$ times for each copy of each journal, where $X$ is related to the frequency of publication. If the journal is published weekly, 5 copies of each distribution card are printed for each month's run; if biweekly, 2 copies; if monthly, bimonthly, quarterly or irregularly, 1 copy.

The reorder list contains the names and addresses of the journals which should be reordered two months from each run.

The complete lists of circulating and reference room copies and libraxy holdings are available if indicated on the master control card for each run. The list of journals circulated to each person is also optional.

Sample Output from the Program

THE FOLLOWING JOURNALS ARE CIRCULATED AT PRESENT
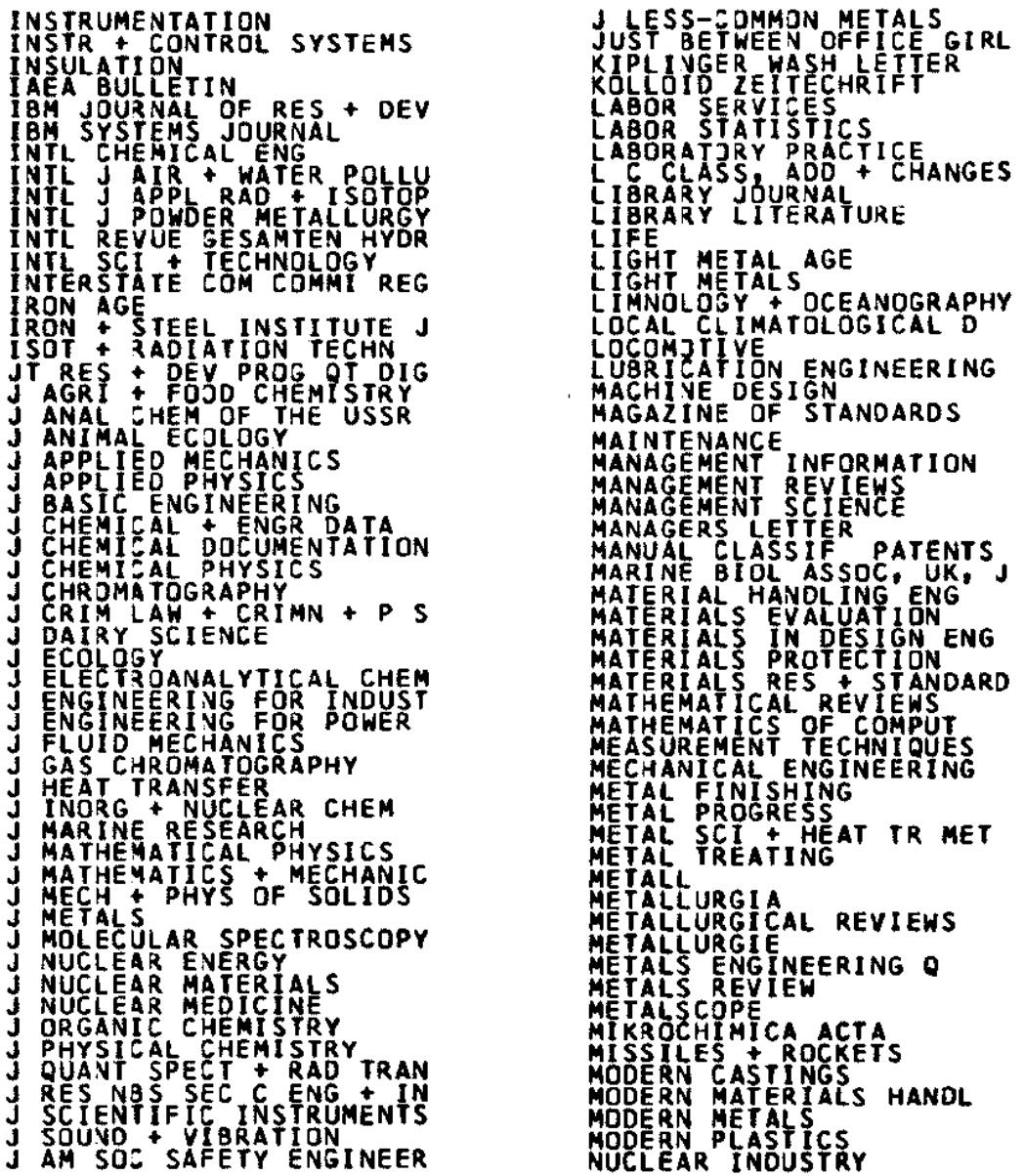
DAHLEN,PA $\quad 704 C$

THIS IS AA LIST OF JOURNALS CIRCULATED TO YOU BY TIS.

IF YOU YO LONGER DESIRE TO READ PA PARTICULAR JOURNAL

ATTACHED LIST, PLEASE INDICATE AND RETURN TO TIS.

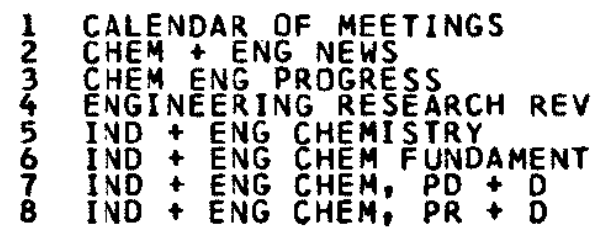


Distribution Lists
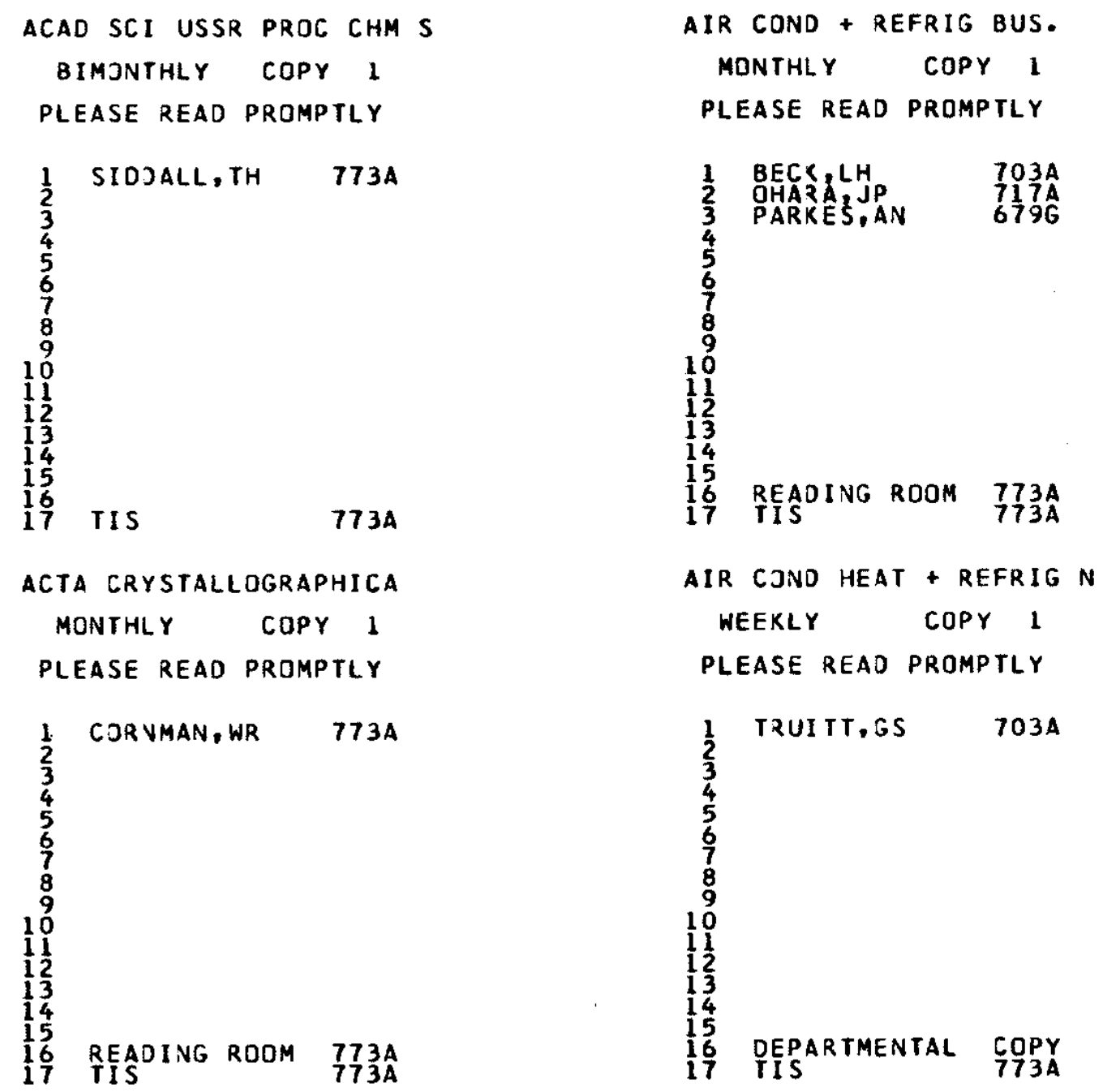

aDMIN MANAGEMENT

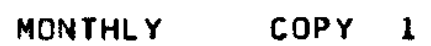

PLEASE READ PROMPTLY

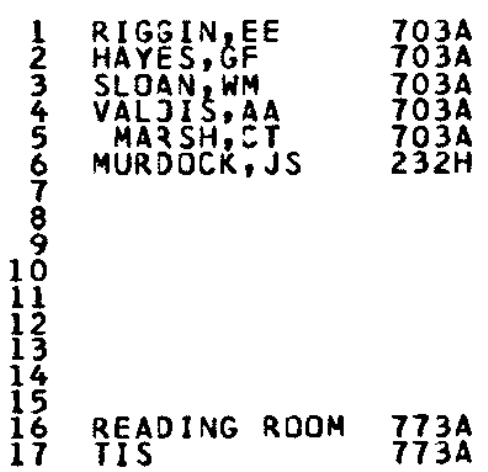
AIR COND HEAT + REFRIG N WEEKLY COPY 1 PLEASE READ PRDMPTLY

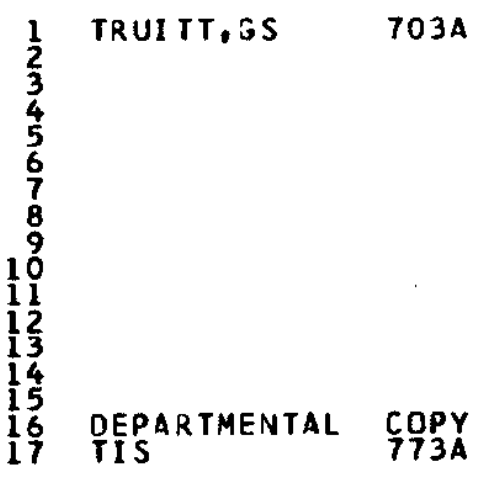



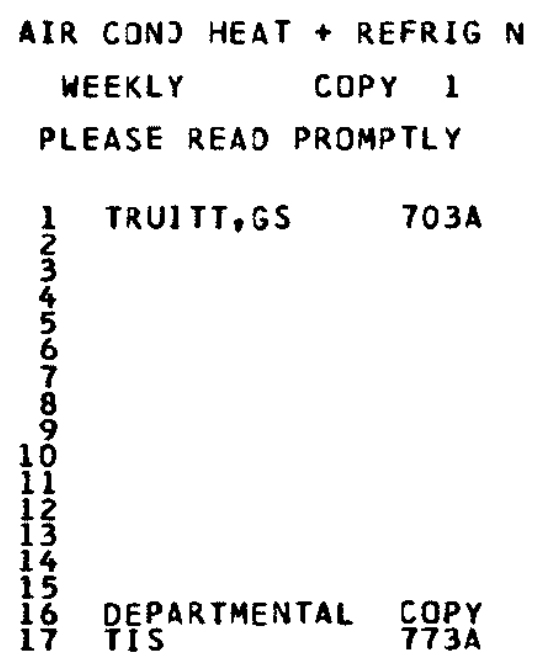

AIR COND HEAT + REFRIG N WEEKLY COPY 1 PLEASE READ PROMPTLY

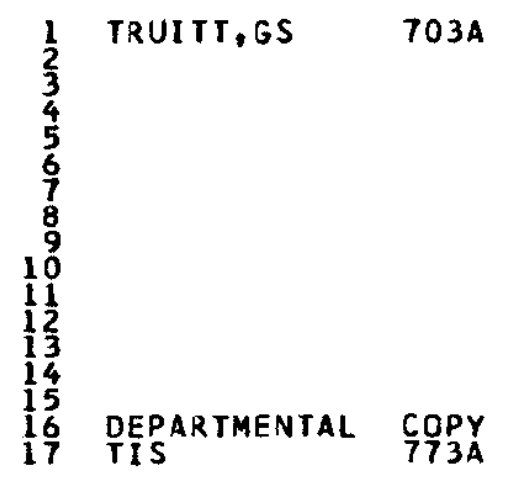

AIR COND HEAT + REFRIG N WEEKLY COPY 1

PLEASE READ PROMPTLY

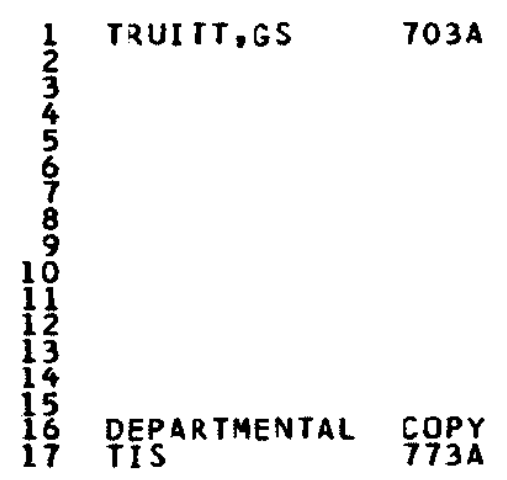

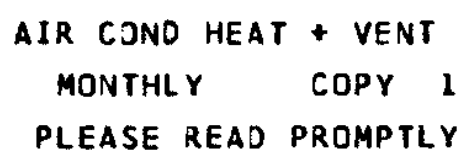

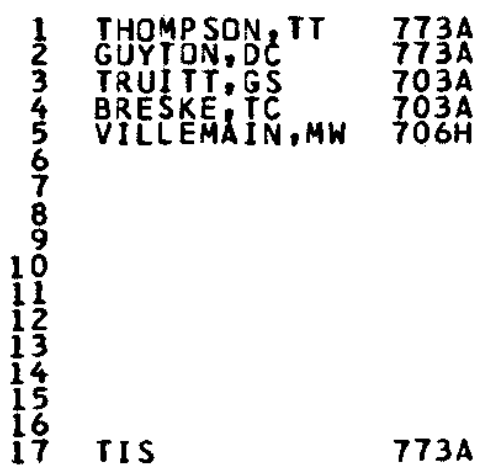

AIR COND HEAT + VENT MONTHLY COPY 2 PLEASE READ PROMPTLY
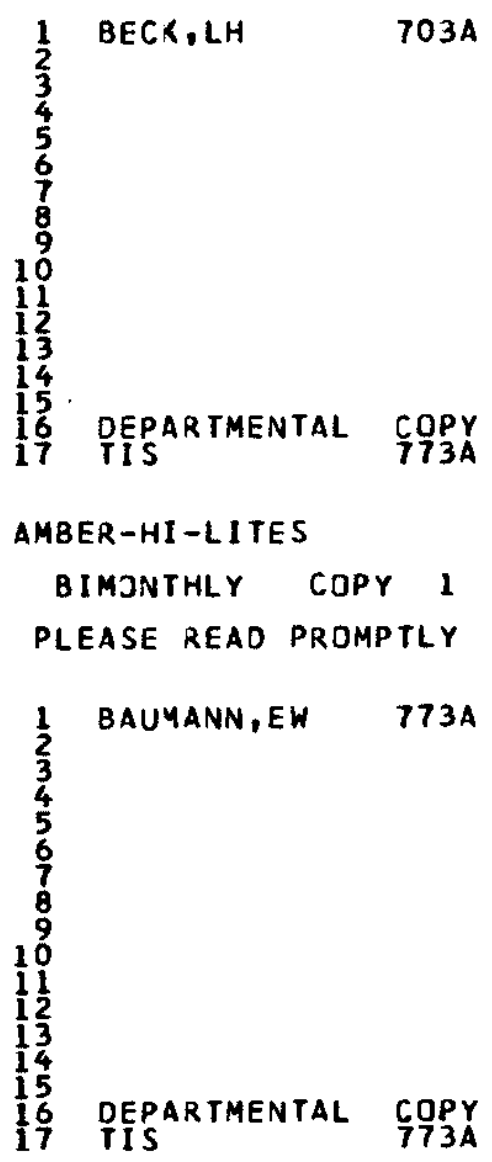
AM ASSOC COST ENGRS BULL QUARTERLY COPY 1 PLEASE READ PROMPTLY

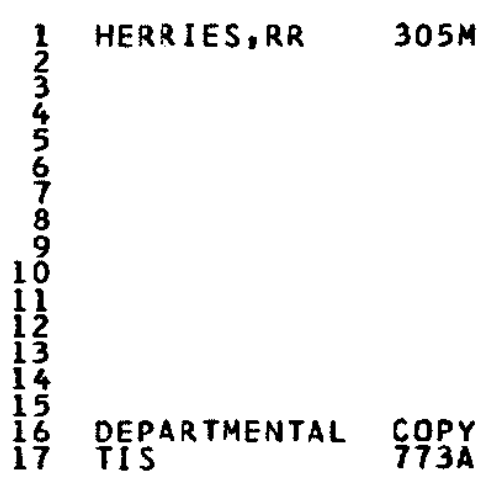

AM CHEM SOC J BIWEEKLY COPY 2 PLEASE READ PROMPILY

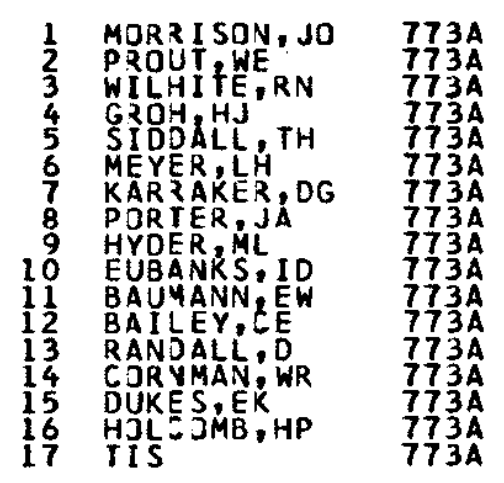

AM CHEM SOC J BIWEEKLY COPY 2 PLEASE READ PROMPTLY

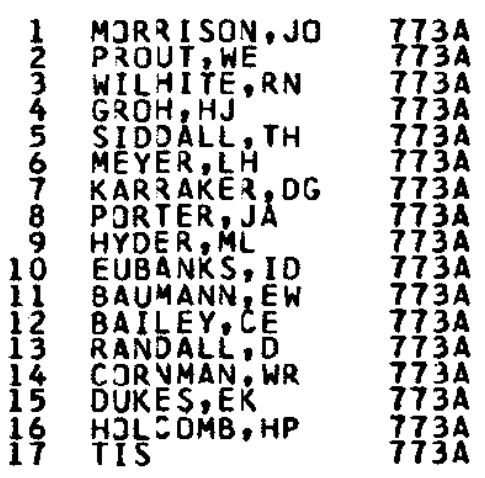

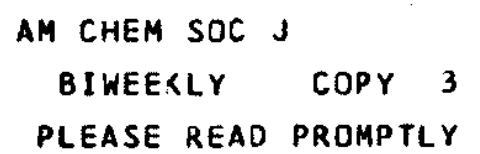

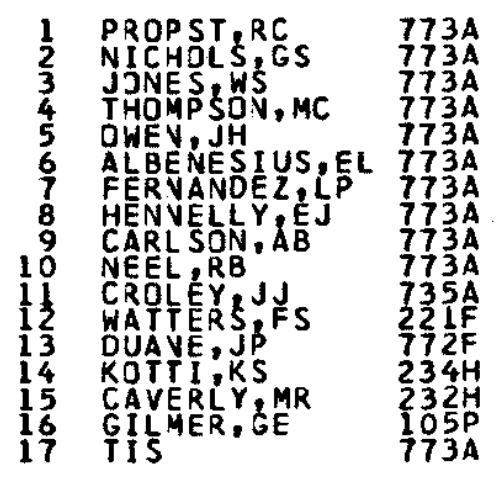

AM CHEM SOC J

BIWEEKLY COPY 3

PLEASE READ PROMPTLY

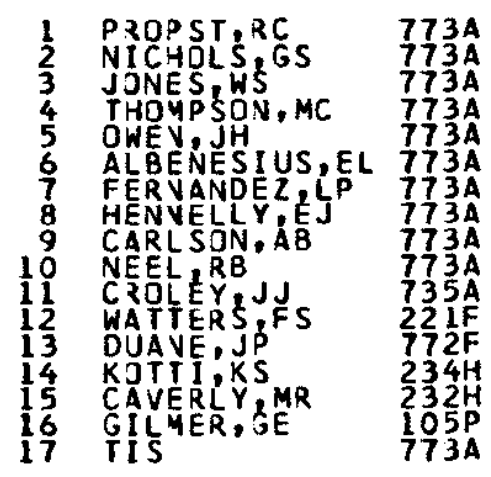

AM DOCUMENTATION QUARTERLY COPY 1 PLEASE READ PROMPTLY

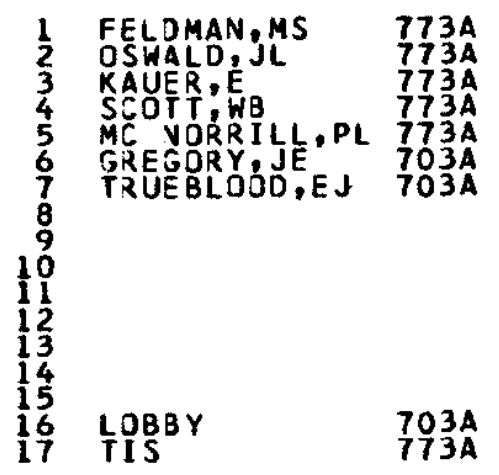


THIS IS A LIST OF JOURNAL HOLDINGS IN TIS LIBRARY ACADEMY DF SCIENCES USSR, PROCEEDINGS OF THE CHEMISTRY SECTION ACTA ERYSTALLOGRAPHICA

ADMINISTRATIVE MANAGEMENT

AIR CJNDITIJNING + REFRIGERATION BUSINESS

AIR CJNDITIONING, HEATING + REFRIGERATION NEWS

AIR CJNDITIONING, HEATING + VENTILATING

AMBER-HI-LITES

AMERICAV ASSOCIATION OF COST ENGINEERS BULLETIN

AMERICAN CHEMICAL SOCIETY, JOURNAL

AMERICAV DOCUMENTATION

AMERILAN INOUSTRIAL HYGIENE ASSOCIATION, JDURNAL

AMERISAV INSTITUTE OF CHEMICAL ENGINEERS, JJURNAL

AMERICAY JOURNAL OF NURSING

AMERICAN JOURNAL OF PHYSICS

AMERICAN MACHINIST

AMERIGAV NATURALIST

AMERICAV SOLIETY HEATING REFRIGERATING + AIR CDNDITIONING ENGR, J. AMERICAN WATER WORKS ASSOCIATION, JOURNAL OF THE

ANALYST

ANALYTIEA CHIMICA ACTA

ANALYTILAL ABSTRACTS

ANALYTISAL. CHEMISTRY

ANNALS JF CHEMISTRY

ANNALS JF INTERNATIONAL MEDICINE

ANNALS JF PHYSICS

APPLIED PHYSICS. LETTERS 
OROER THE FOLLOWING JOURNALS BY THE IOTH MONTH OF THE YEAR

ELECTRICAL EQUIPMENT

SUTTOY PUBLISHING CO, INC

172 SJUTH BROADWAY
WHITE PLAINS, NY

ELECTRICAL WORLD

MC GRAW HILL PUBLISHING CO,INC

330 WEST 42 ND STREET

NEW YJRK 36, NY

ELECTROEHEMICAL SOCIETY, JOURNAL ELEC TROFHEMICAL SOCIETY, INC

NEW YORK, NY 10017

ELECTROCHEMICAL TECHNOLOGY

ELECTROCHEMICAL SOCIETY, INC

NEW YORK, NY 10017

ELECTRONICS

MC GRAW HILL PUBLISHING CO INC 330 WEST 42 ND STREET

NEW YORK 36, NY

ELECTRO-TECHNOLOGY

A CANJNER-MAST PUBLICATION

205 EAST 42ND STREET

NEW YORK IT, NY

ENDEAYOUR

IMPERIAL CHEMICAL INOUSTRIES

$S$ BLOCK, IHAMES HUUSE MILLBANK

LONDON, SWI, ENGLAND

ENGINEERING NEWS-RECURD

MC GRAW HILL PUBLISHING CO INC

330 WEST 42 ND STREET

NEW YORK 36, NEW YORK

ENGINEERING PROGRESS

E I DUPJNT DE NEMOURS + CD

ENGINEER ING DEPT.

WILMINGTON, DELAWARE

ENG INEER ING RESEARCH REVIEW

E I DUPJNT DE NEMOURS + CO

ENGINEERING DEPT

WILMINGTON, DELAWARE

FACTORY

MC GRAW HILL PUBLISHING CO INC

330 WEST 42ND STREET

NEW YDRK 36, NEW YORK

FAMILY SAFETY

E I DUPJNT DE NEMOURS + 60

WILMINGTON, DELAWARE

FILM ENGINEER ING NEWS

E I DUPJNT DE NEMOURS + CD

FILM DEPT IND SALES RM N-10452

WILMIVGTON, DELAWARE 19898

FOCUS

NATIONAL IND CONF BOARD, INC

845 THIRD AVENUE

NEW YORK, NEW YORK 10002 


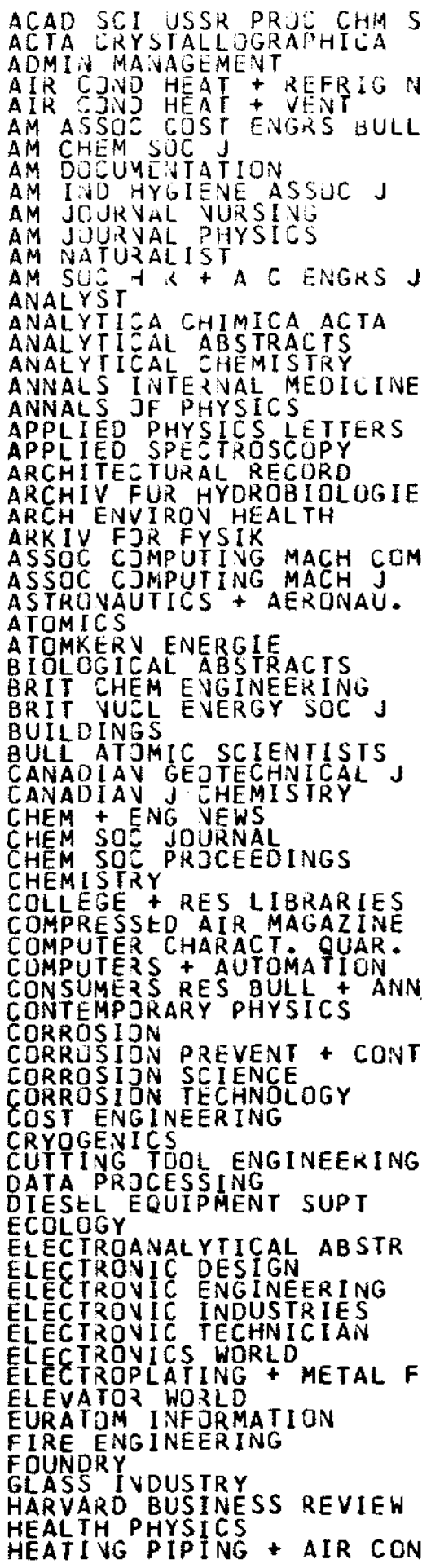

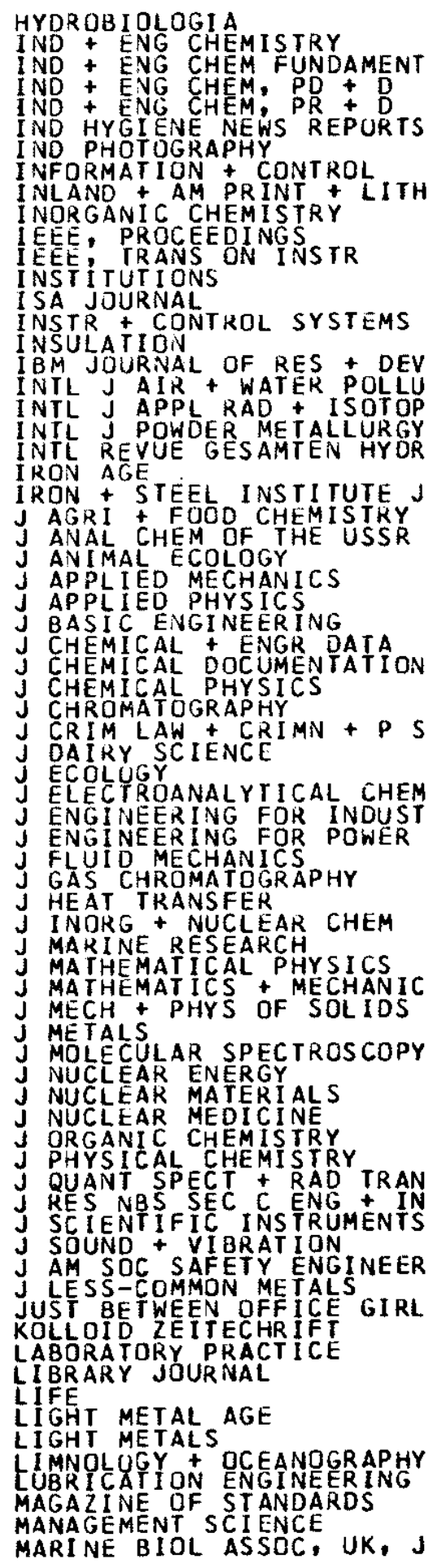




\section{HANDLING PROCEDURES AND OPERATING INSTRUCTIONS}

Handling procedures are simple and straightforward. The library staff keeps a card file which is set up like the master tape. It is updated periodically and it is from this file that the master tape is updated.

The master tape is made only once (CTX, off-line). It is updated each month if necessary, and printed off-line. The output is printed off-line.

The program is kept in the machine room. The master control card and the change cards are submitted with an instruction card.

Operating instructions are as follows: The master tape from the previous run is mounted on tape unit 6. All input is put on tape 7 . If changes are made, the new master tape is generated on tape 8 . The old master tape on unit 6 is marked and retained; the new master tape is labeled, dated, and stored.

Output is on unit 10. Units 4 and 5 are scratch tapes. Instructions from the printer are pertinent. An HPR 12345 on the console indicates the end of the run. The output tape is printed off-line, 8 lines per inch, on unlined paper. If the master tape was updated, the new master tape is printed off-line, without carriage control before it is stored. 
FORTRAN Listing of the Program

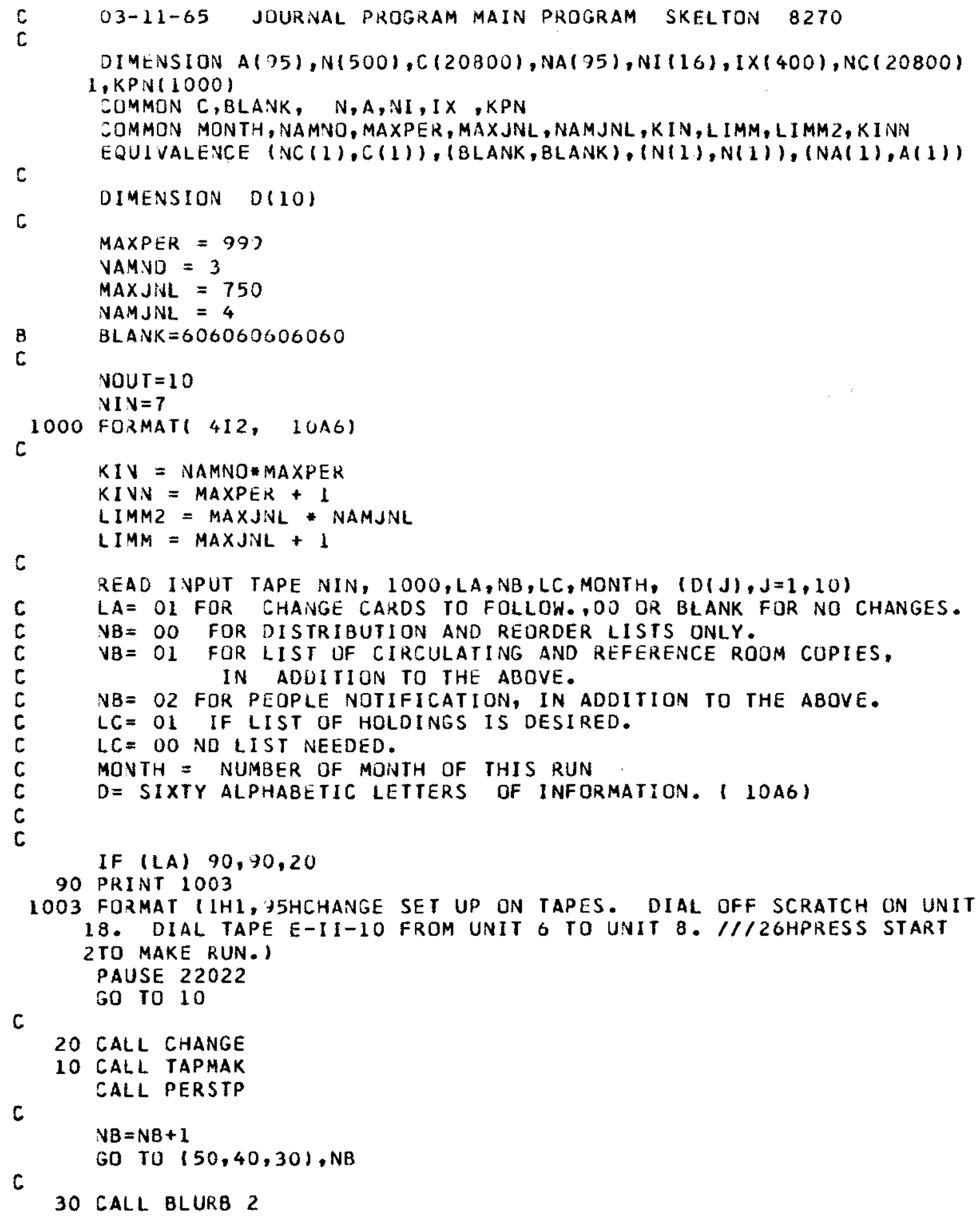




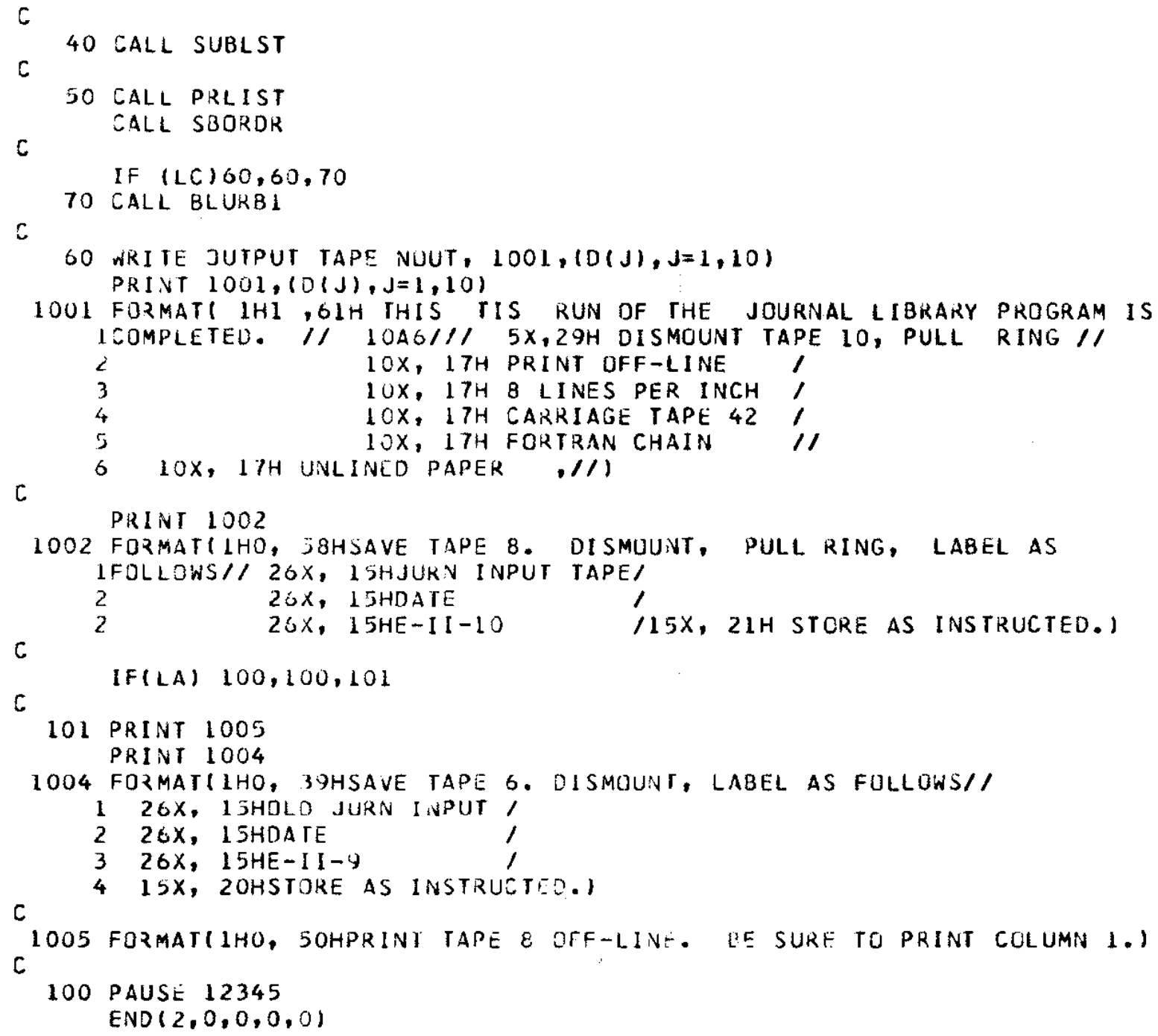




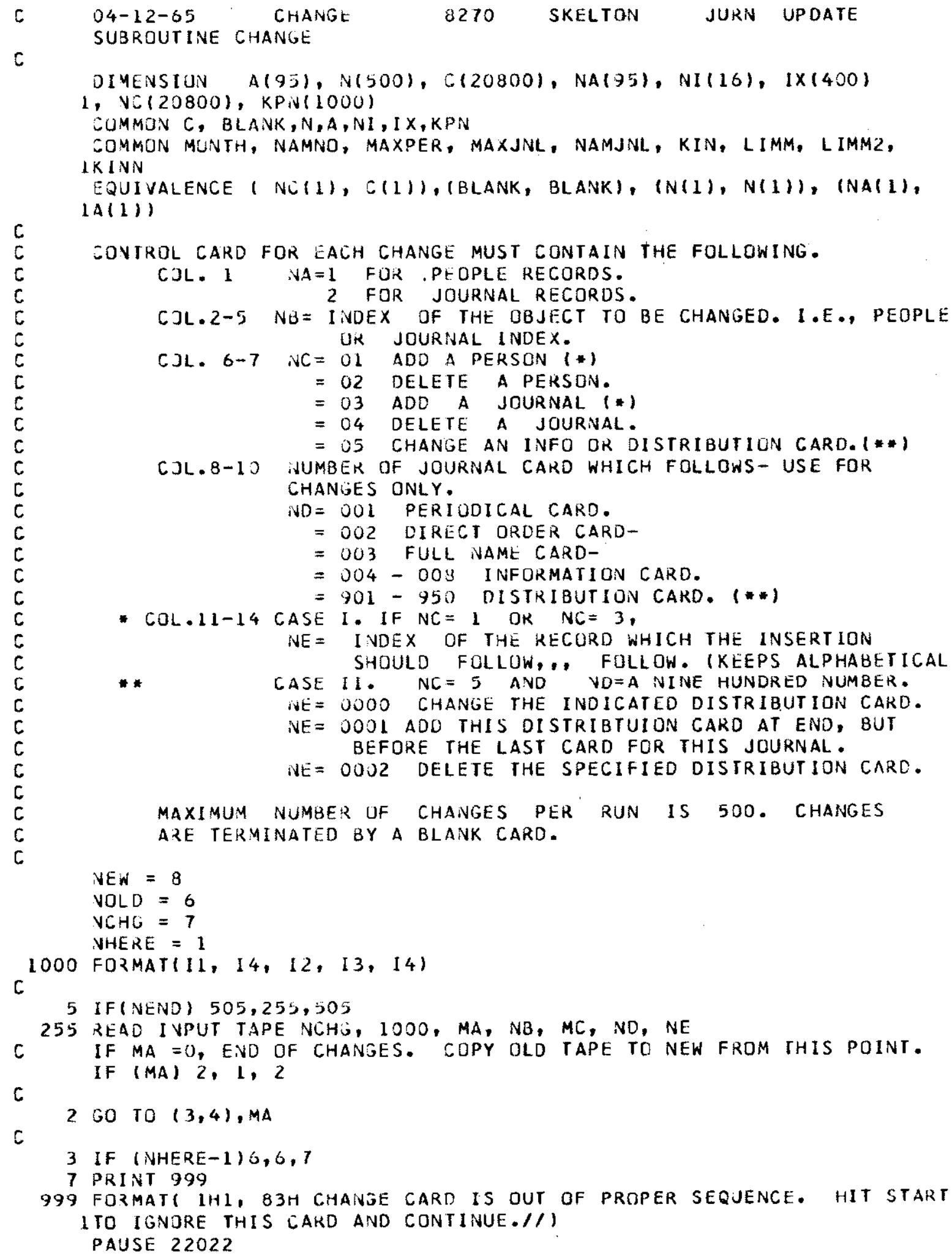




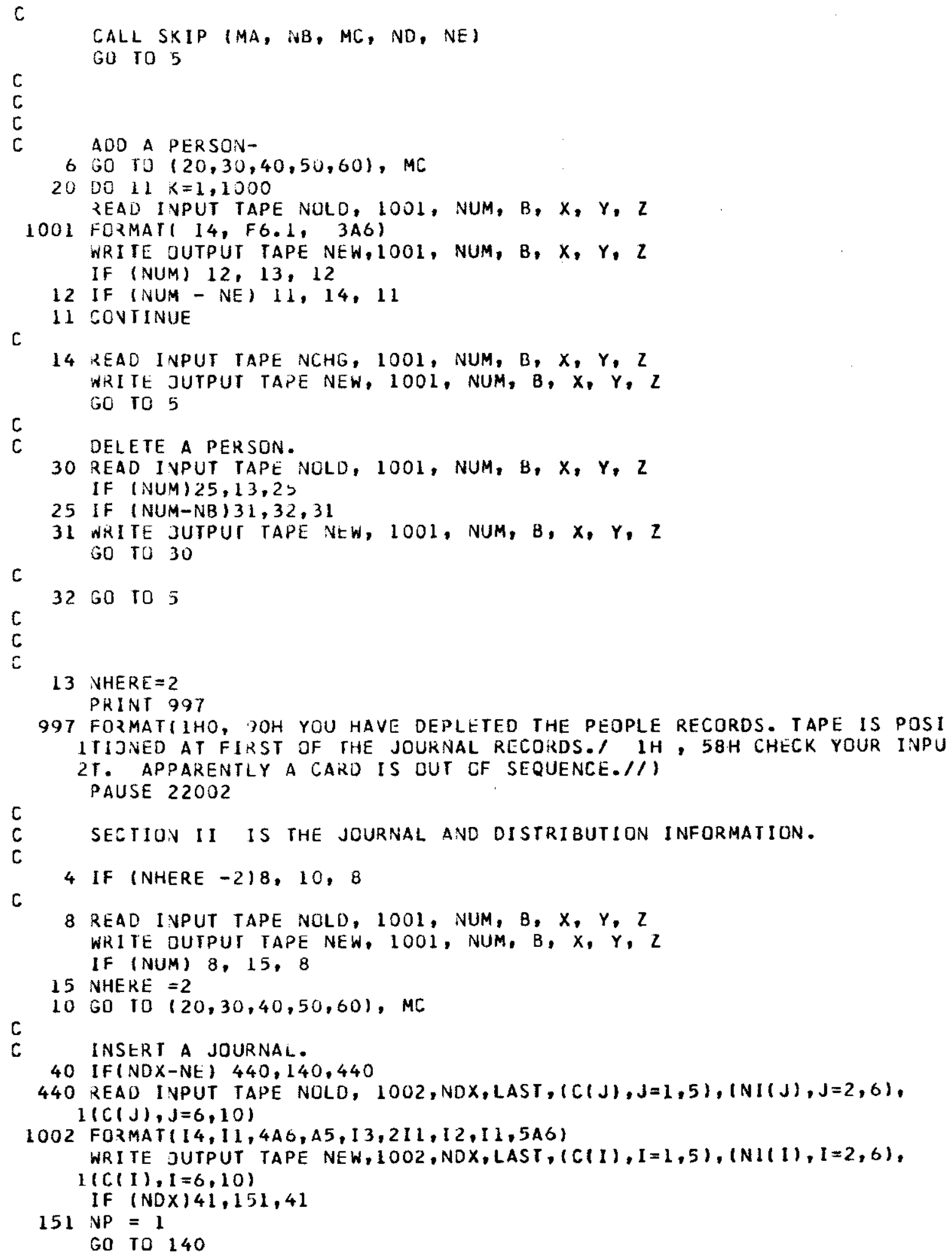


$c$

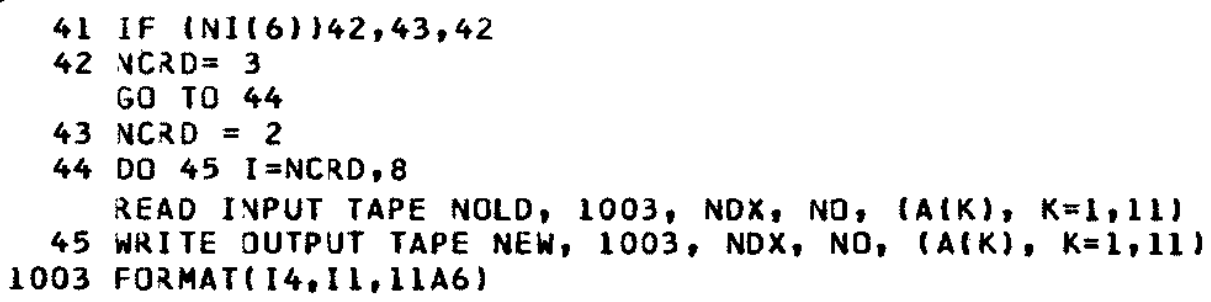

delete a journal. 
C

50 VFIND $=0$
150 READ INPUT TAPE NOLD, 1002, NDX, LAST, $(C(K), K=1,5),(N I(K), K=2,6)$, $1(C(K), K=6,10)$ IF (NDX) $51,500,51$

51 IFINDX-NB) $52,59,52$

52 WRI TE OUTPUT TAPE NEW, 1002, NDX, LAST, $(C(K), K=1,5),(N I(K), K=2,6)$, $1(C(K), K=6,10)$ IFI NI(6)) $53,54,53$

53 VC२D $=3$ GO 1055

$54 V C R D=2$

55 DO $56 \quad I=N C R O, 8$ READ IVPUT TAPE NOLD, 1003, NDX, LAST, (A(K), K=1,11)

C

56 WRITE JUTPUT TAPE NEW, 1003, NDX, LAST, (A(K), K=1,11)

57 READ I.VPUT TAPE NOLD, 1004, NUX, ND, NP, NDPT, (NI(K),K=1,16) WRITE JUTPUT TAPE NEW,1004, NDX, ND, NP, NDPT, (NI(K),K=1,16) I $F(N O) 57,57,58$

58 IF(NFIND-1) $150,100,504$

C

59 READ IVPUT TAPE NOLO, $1004, N O X, N O$

IF (NO) $5,59,5$

C

c

C

$60 V E=N E+1$

LOJP $=1$

C CHANGES ONLY.

100 READ I VPUT TAPE NULD, 1002 , NDX,LAST, $(C(K), K=1,5),(N I(K), K=2,6)$,

$1(C(K), K=6,10)$

$\mathrm{NDE}=1$

IF (NDX) $502,500,502$

502 I $F(N D X-N B) \quad 503,504,503$

503 NFIND=1

GO TO 52

504 LOJP $=2$

IF $(N D-1) 105,102,105$

102 ZEAD INPUT TAPE NCHG, 1002 , NDX, LAST, $(C(K), K=1,5),(N I(K), K=2,6)$, $1(C(K), K=6,10)$

WRITE JUTPUT TAPE NEW, $1002, N D X$, LAST, $(C(K), K=1,5),(N I(K), K=2,6)$,

$1(C(K), K=6,10)$

READ INPUT TAPE NCHG, $1000, M A 2, N B 2, M C 2, N D 2, N E 2$

IF (MA2) $300,1,300$

300 IF (NDX - NB2)119,703,119

$703 \mathrm{ND}=\mathrm{ND} 2$

$N E=N E 2+1$

$M C=M C 2$

GO TO 115

105 WRITE JUTPUT TAPE NEW, 1002 , NDX,LAST, $(C(K), K=1,5),(N I(K), K=2,6),(C$ I(K), K=6,10)

GO TO 115

119 BAEKSPACE NCHG

$N D=99$

$N E=1$ 


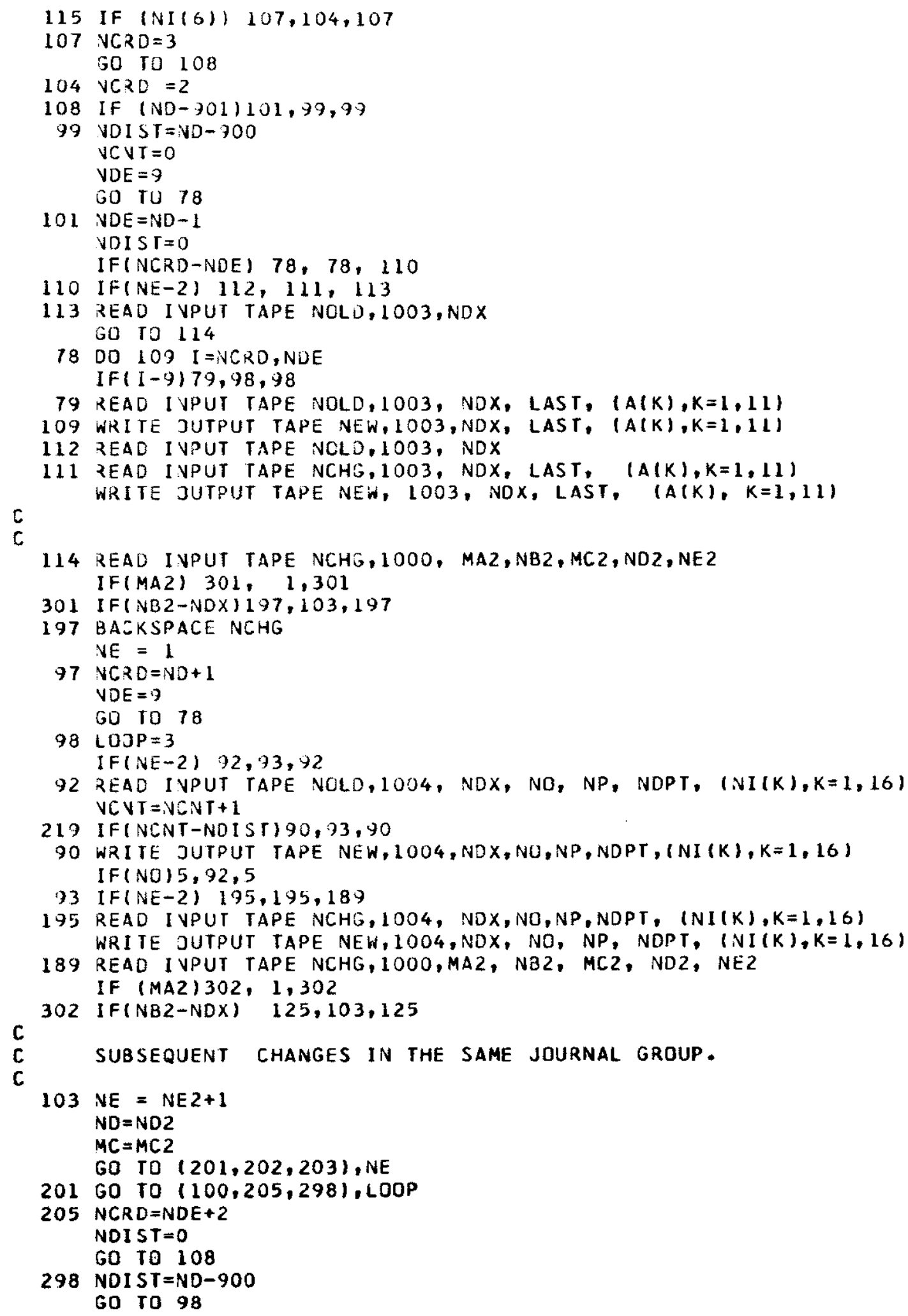




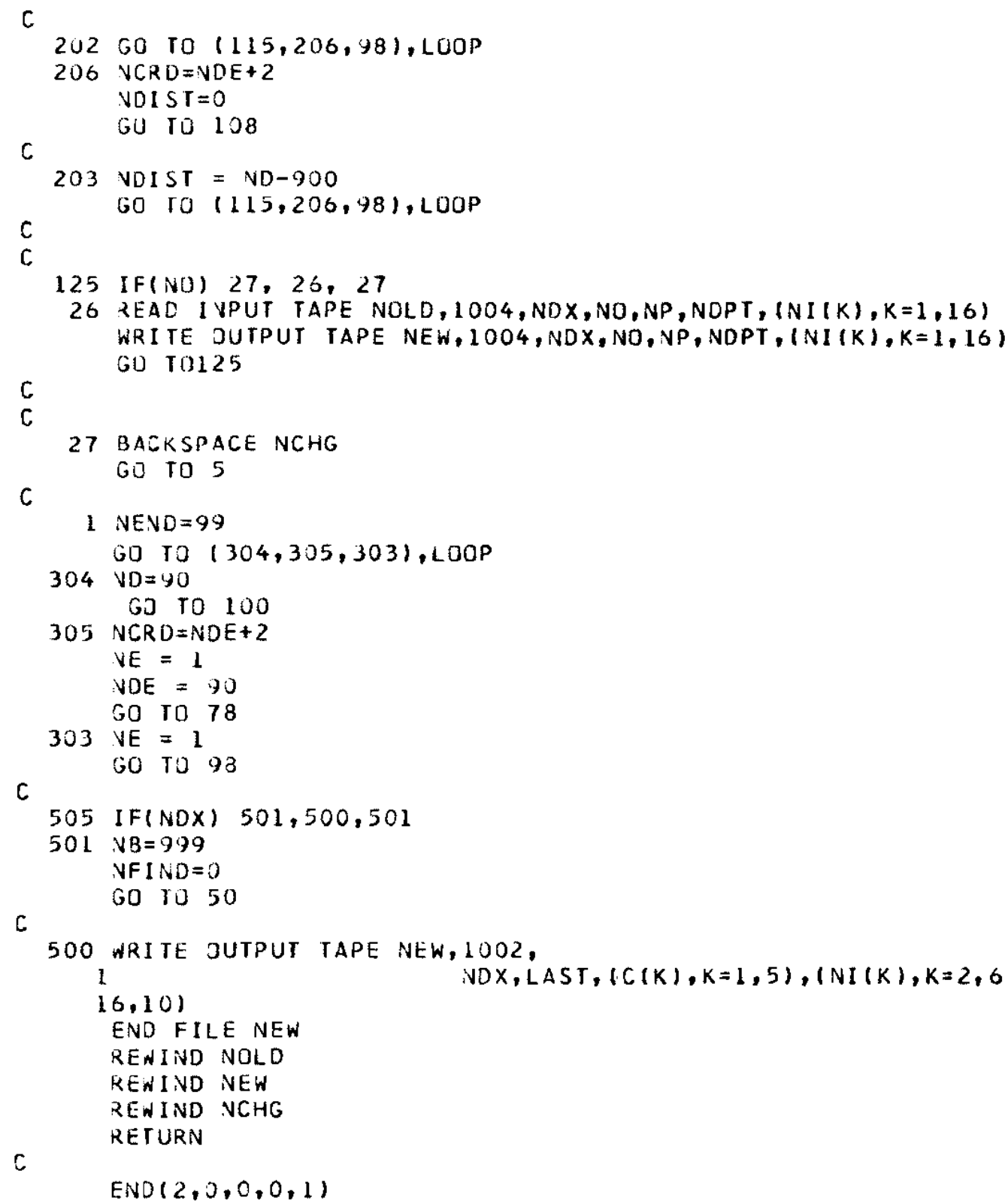




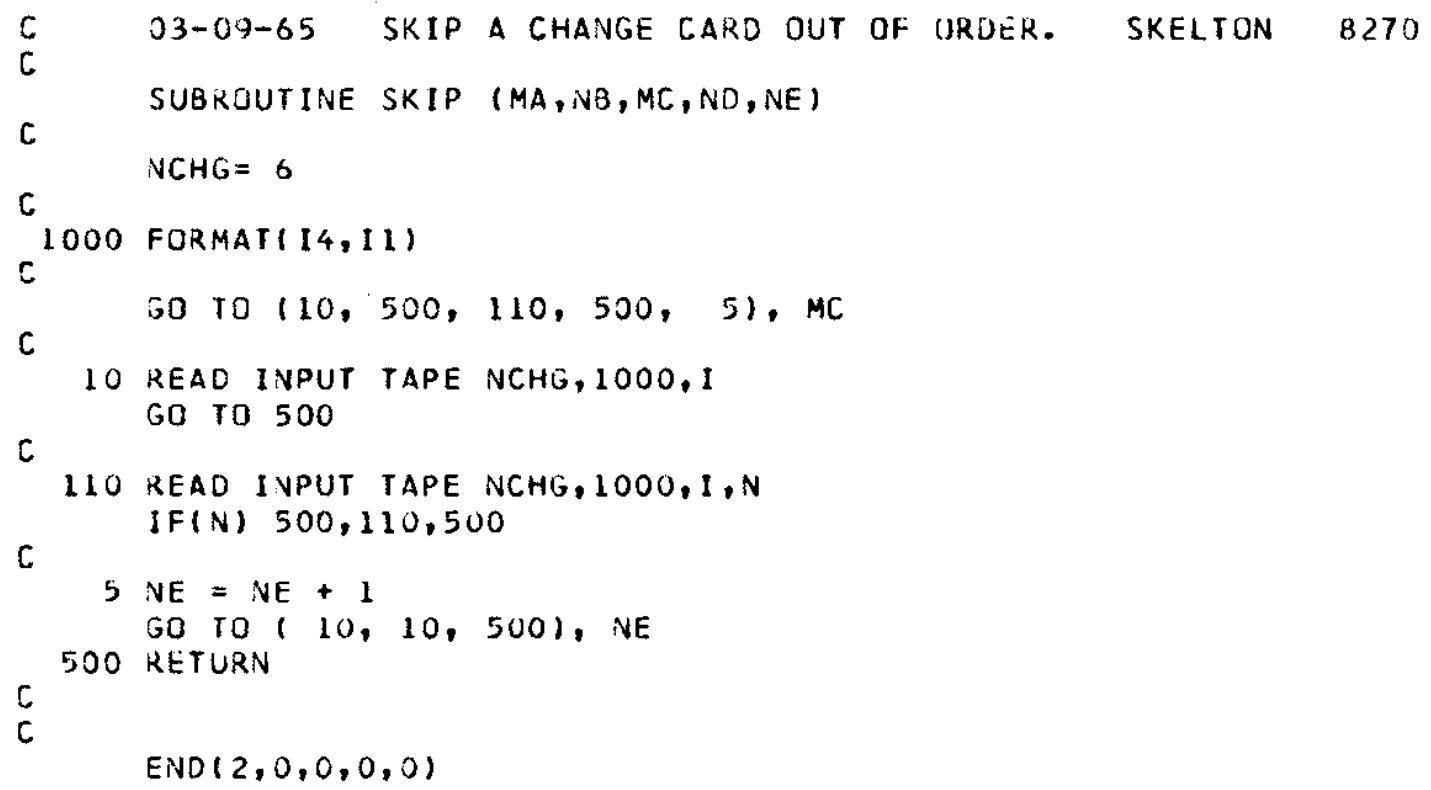


C DO O I = I, LIMM

REAO IVPUT TAPE NTIN, $, K, J, X, Y, Z, V, U, N 1, N 2, N 33, N 3, N 4,(A(L), L=13,17$ 1)

7 FORMAT( $14,11,4 A 0, A 5,13,211,12,11,546)$ $I F(K) 9,8,3$

$9, V J=4 *(K-1)+1$

$V A(1)=K$

$C(V J)=x$

$C(V J+1)=r$

$C(v J+2)=2$

C

$C(v J+3)=V$

C TESTING FOR THE FREQUENCY UF PUBLICATION. WHEN TEST=U-1.OEX

C THE 1.OEX HAS SLMETHING TO DO WITH THE INTERNAL REPRESENTATION OF

C A FLIATING PUINT NUMBER. EXAMPLE, 1.OE-25 HAS AN INTERNAL FORM OF

C 24XXXXXXXXXXXXXXXXX. THERTFURE, WHEN SUBTRACTER FROM THE VALUE

C OF $U$, THE ALPHABETIC CHARACTER OF THE LETTER CAN BE DETERMINED.

C

If (U) $10,11,11$

$10 U=A B S F(U)$

TES T $=\mathrm{U}-1.0$

IF(TEST) $12,12,13$

$13 \quad A(2)=0.0$

GO TO 14

12 TEST $=U-1.0 E-25$

IF(TEST) $15,15,16$

C

FREQUEVCY OF PUBLICATION IS WEEKLY.

$16 \quad A(2)=4.0$

C

GO TO 14

C FREQUEVCY OF PUBLICATION IS MONTHLY OR QUARTERLY.

$15 \quad A(2)=2.0$

601014

C

FREQUEVCY OF PUGLICATION IS BIWEEKLY, IRREGULAR, OR BIMUNTHLY.

11 TEST $=U-1.0 E 7$

IF(TEST) 17,17,18

$\mathrm{C}$

C FREQUENCY OF PUBLICATION IS IRREGULAR.

$18 A(2)=5.0$

SO $10 \quad 14$

17 TEST $=U-1.0$

IF(TEST) $200,200,201$

C

C FREQUENCY DF PUBLICATION IS BIMONTHLY.

$200 A(2)=3.0$

GOTOI4

c

C FREQUENCY OF PUBLICATION IS BIWEEKLY.

$201 \quad A(2)=1.0$

$14 A(10)=Y$

$A(9)=X$

$A(11)=Z$

$A(12)=V$ 


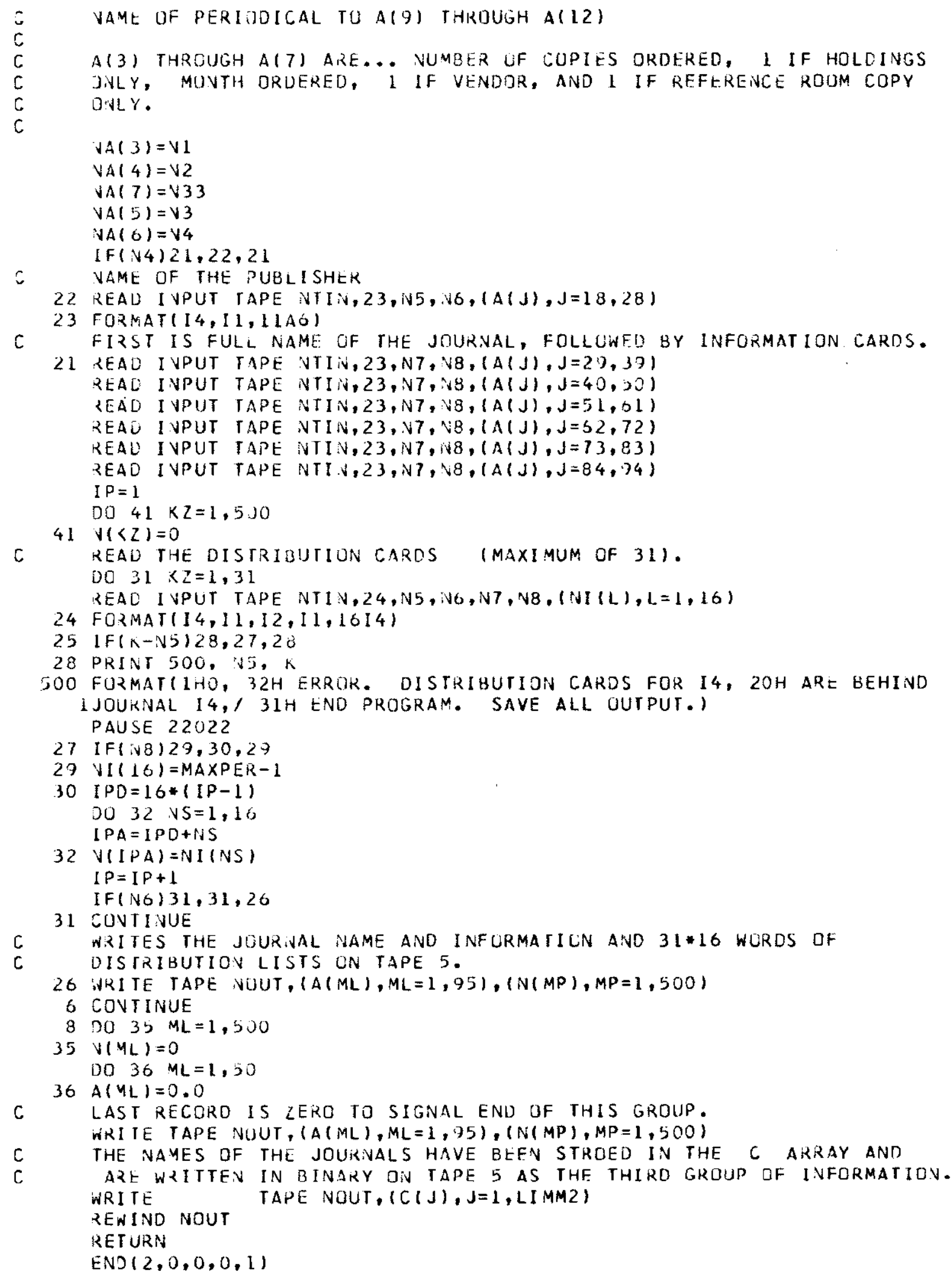




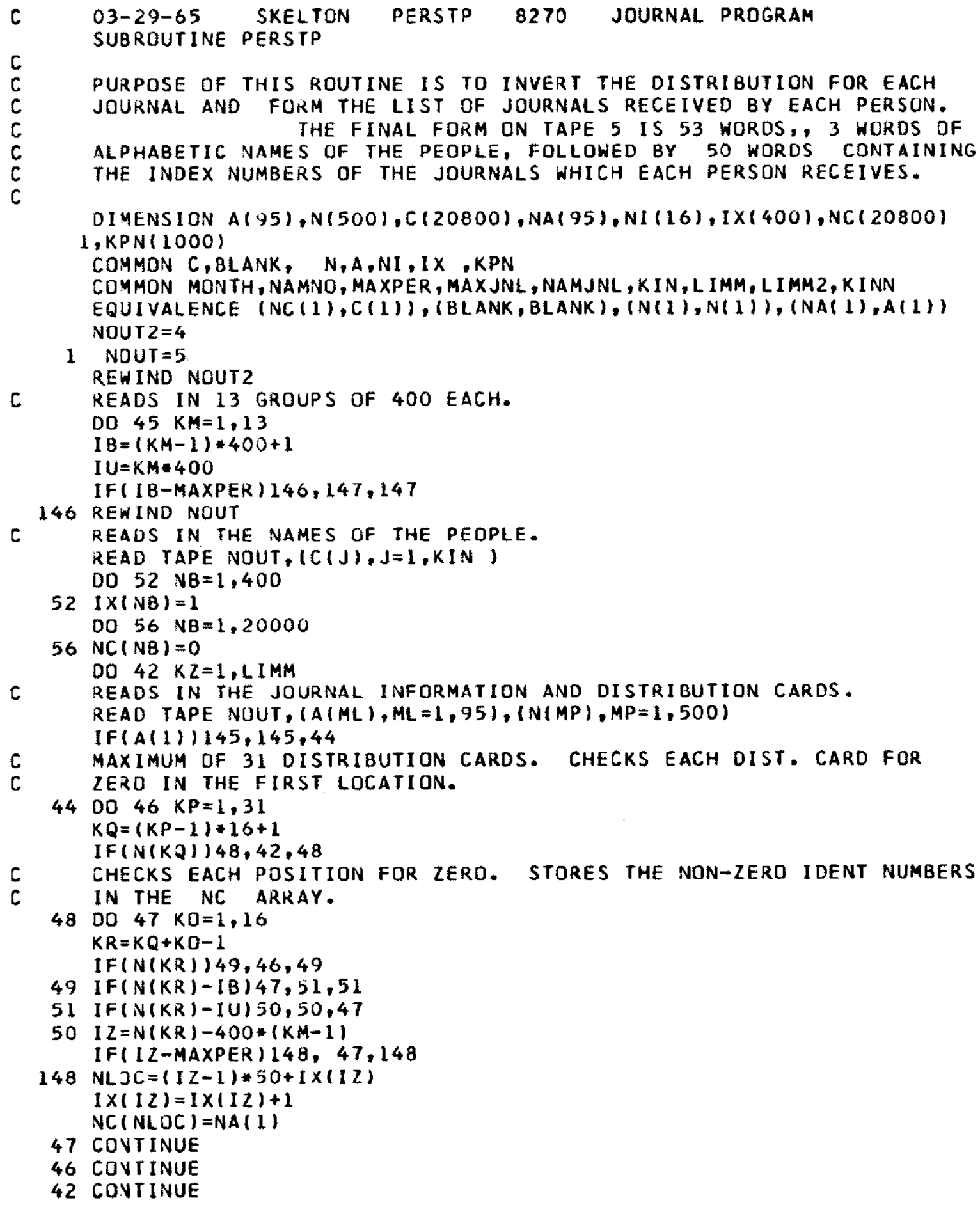




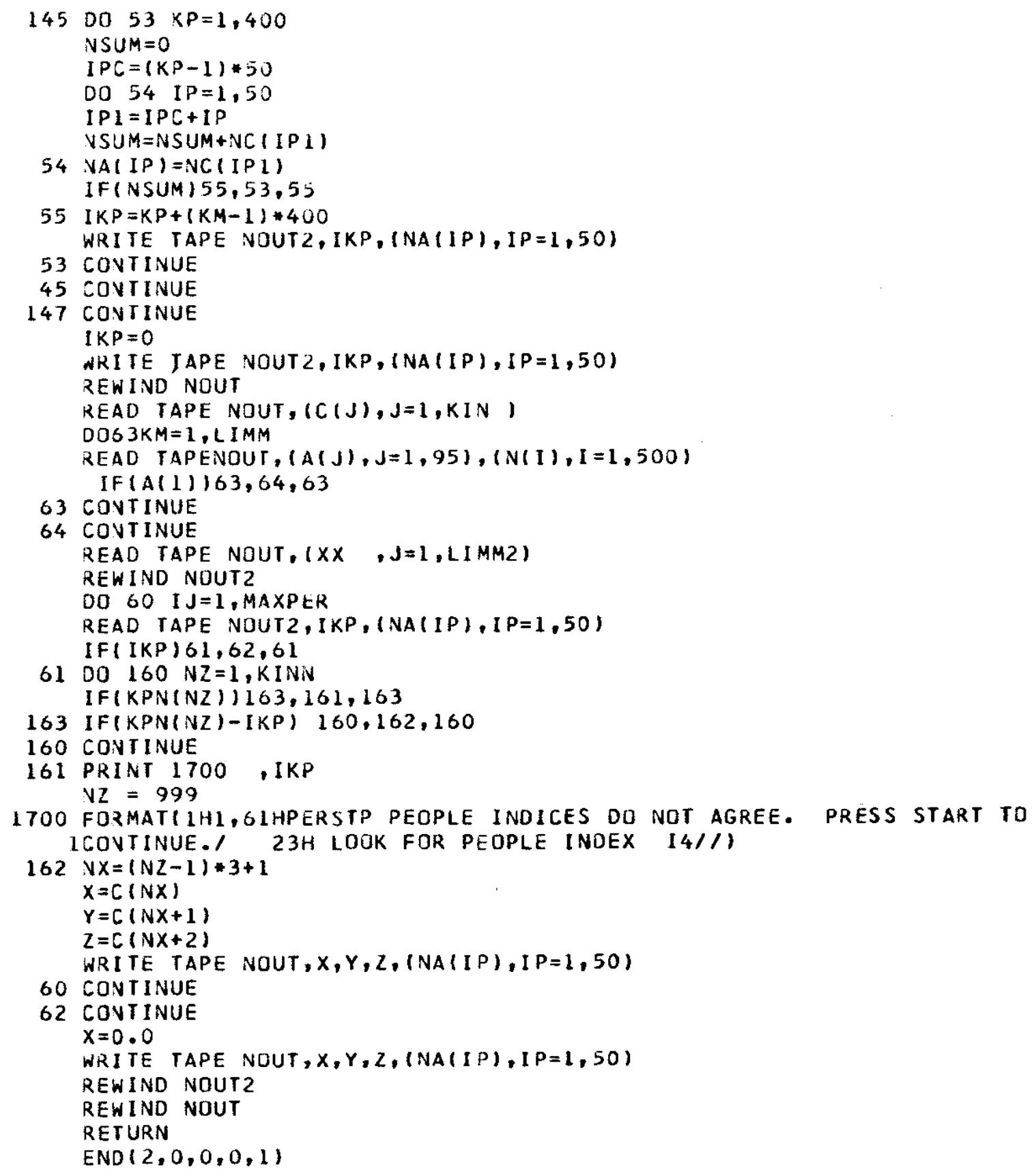




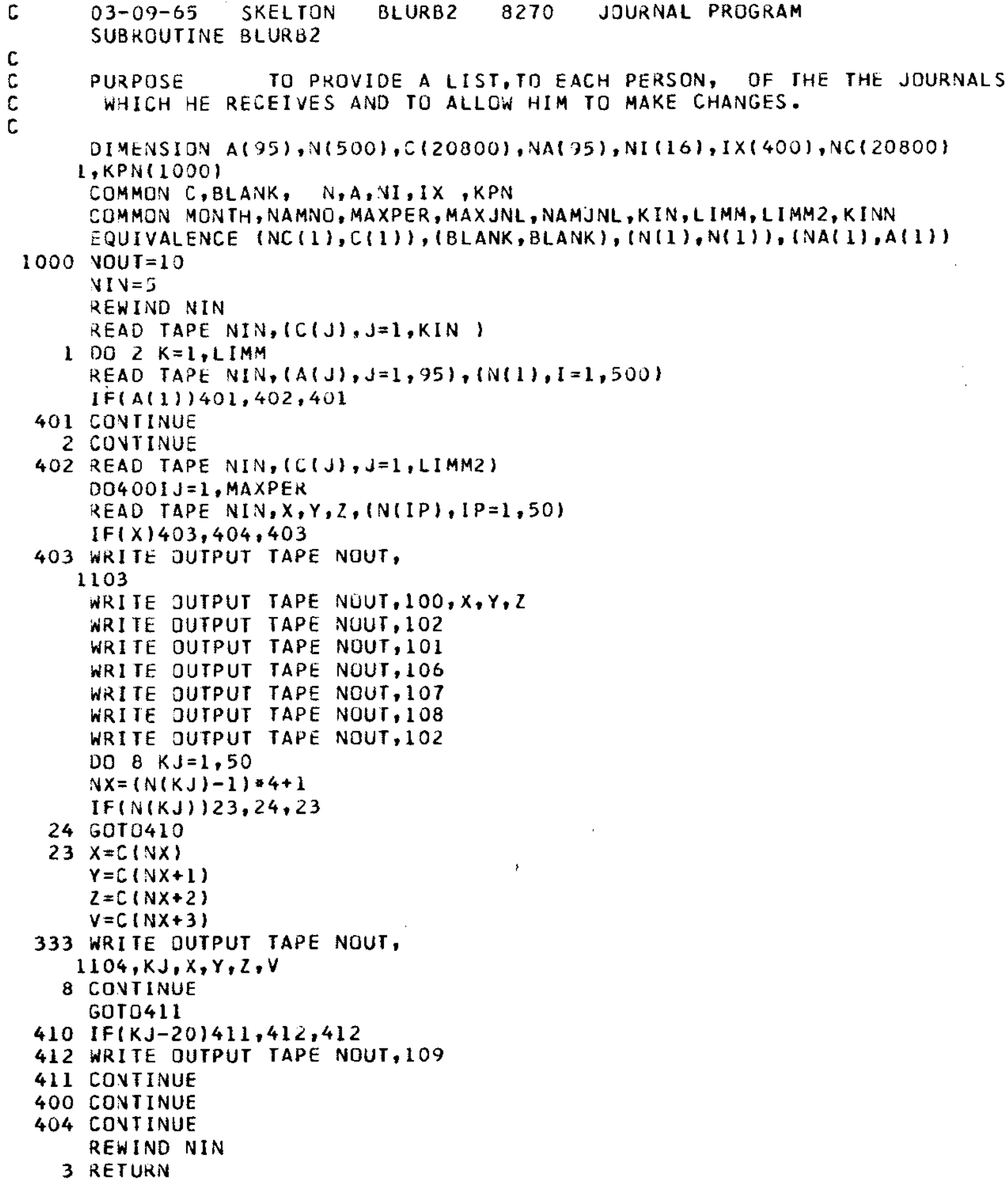




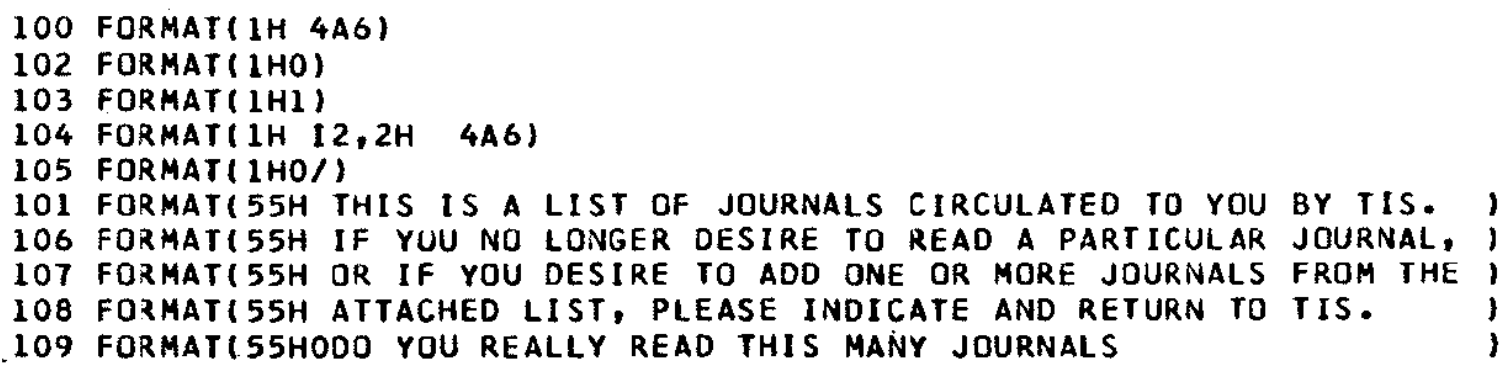




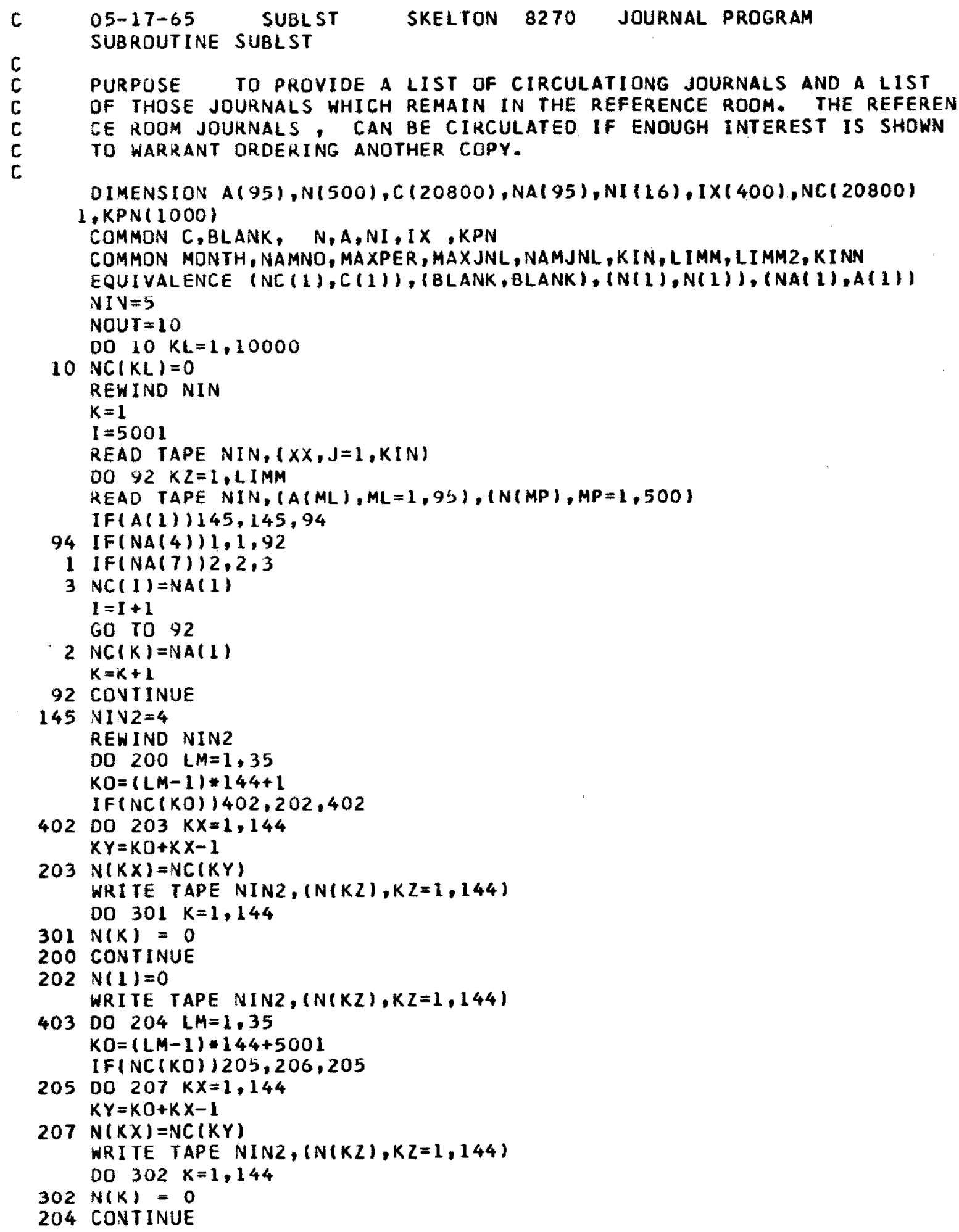




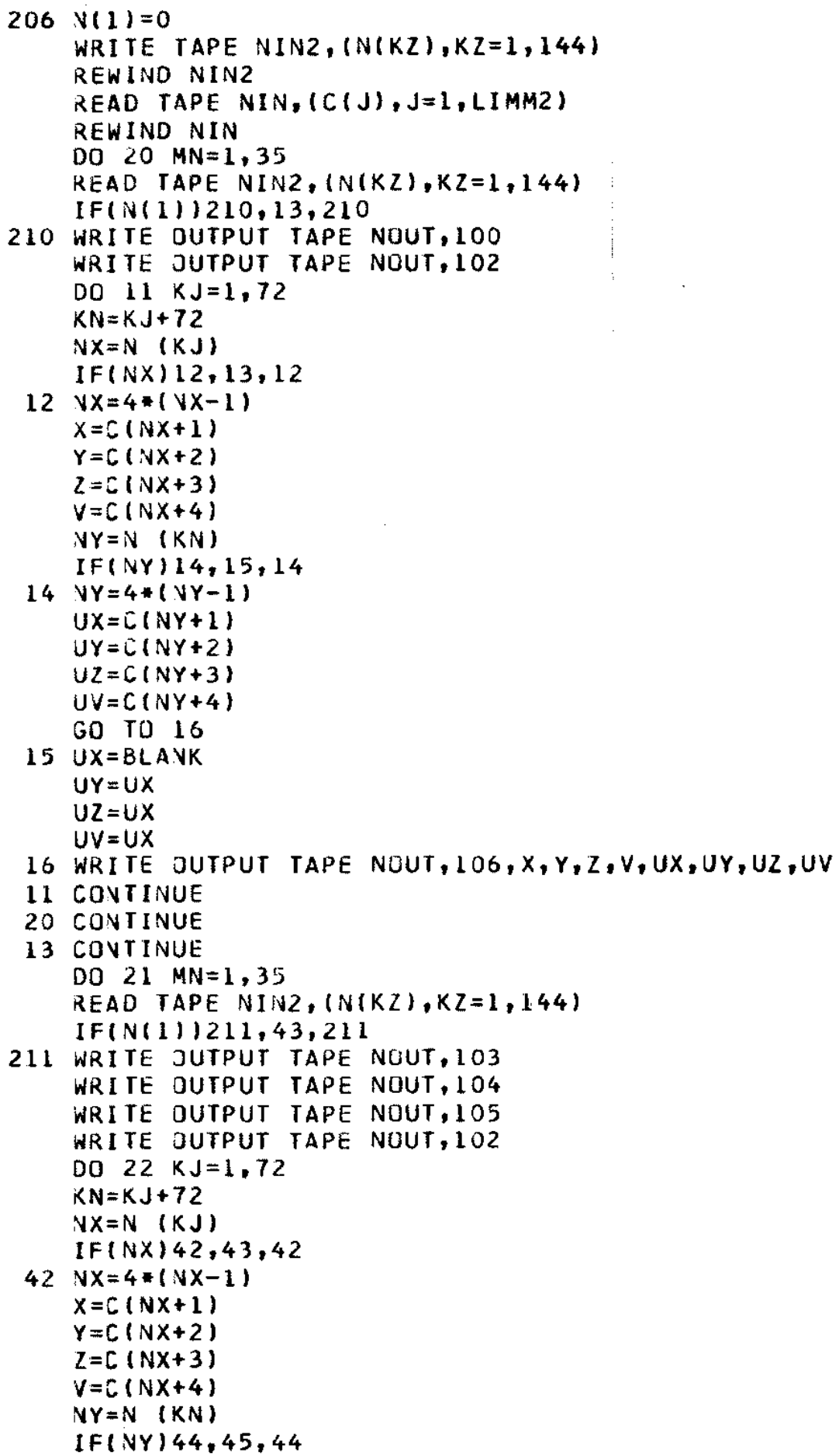




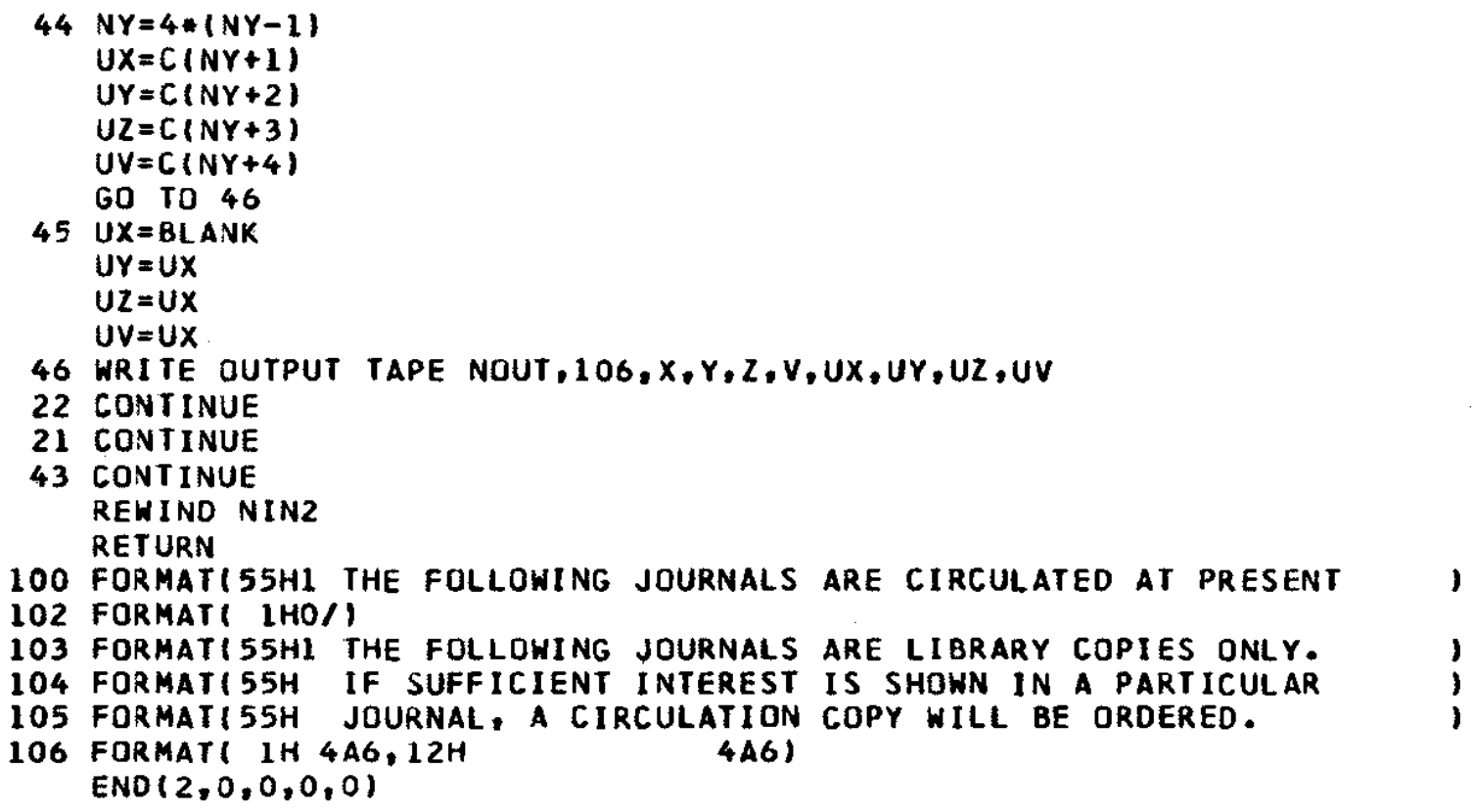




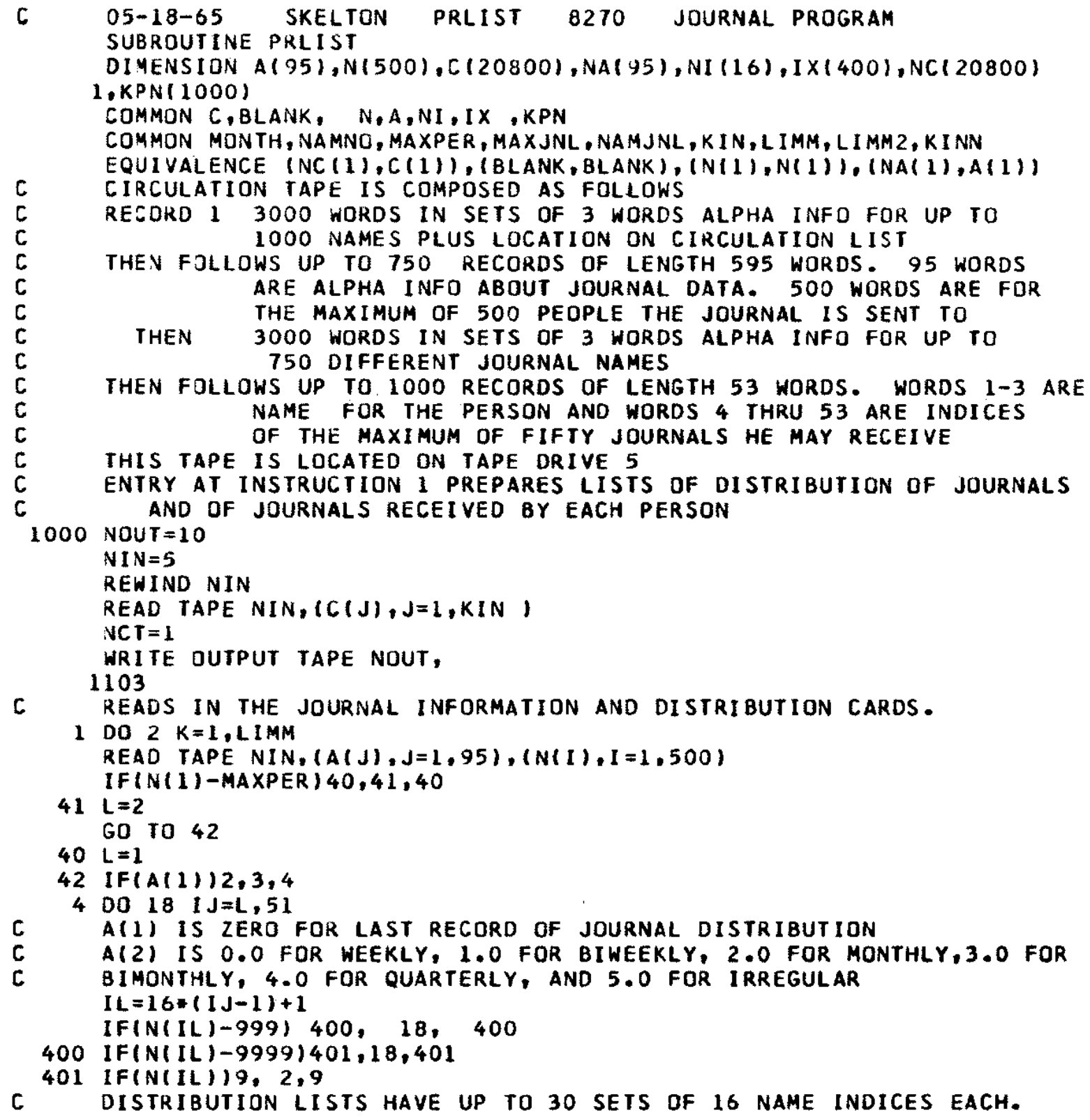


C WHEN FIRST INDEX IN A SET IS ZERO, NO MORE SETS ARE WORKED ON

9 IFI $(2)-1.017,6,5$

7 LEJ $=5$

GO TO 22

6 LEJ $=2$

GO TO 22

$5\lfloor E J=1$

22 DO $28 \quad K N=1, L E J$

WRITE DUTPUT TAPE NOUT,

$1100, A(9), A(10), A(11), A(12)$

$I A=A(2)$

$I A=I A+1$

GO TO $(30,31,32,135,33,34)$, IA

c

30 CONTINUE

WEEKLY
WRITE OUTPUT TAPE NOUT,

1106, IJ

GOT035

31 CONTINUE

c

BIWEEKLY
WRITE DUTPUT TAPE NOUT,

1206, IJ

Gor 035

32 continue

c

MONTHLY
WRITE OUTPUT TAPE NOUT,

1108, IJ

C GOT035

B IMONTHLY

135 WRITE OUTPUT TAPE NOUT,

1107, IJ GOT035

33 CONTINUE

c

WRITE OUTPUT QUAETERLY

$1109,1 \mathrm{~J}$ GOTO35

c

34 CONTINUE

IRREGULAR

WRITE DUTPUT TAPE NOUT,

$1110, \mathrm{IJ}$

35 CONTINUE

WRITE DUTPUT TAPE NOUT, 1101

WRITE OUTPUT TAPE NOUT,

1102

6 WILL WRITE 16 TIMES THE NAMES OF PEOPLe IF AVAILABLe, BLANKS If

C NOT.

DO $8 \mathrm{KJ}=1,16$

$K Y=I L+K J-1$

$N J S=N(K Y)$

DO $224 N Z=1$, $K I N N$

IF(NJS-KPN(NZ)) 224, 225, 224

224 CONTINUE

PRINT 2000, NJS, NA(1) 


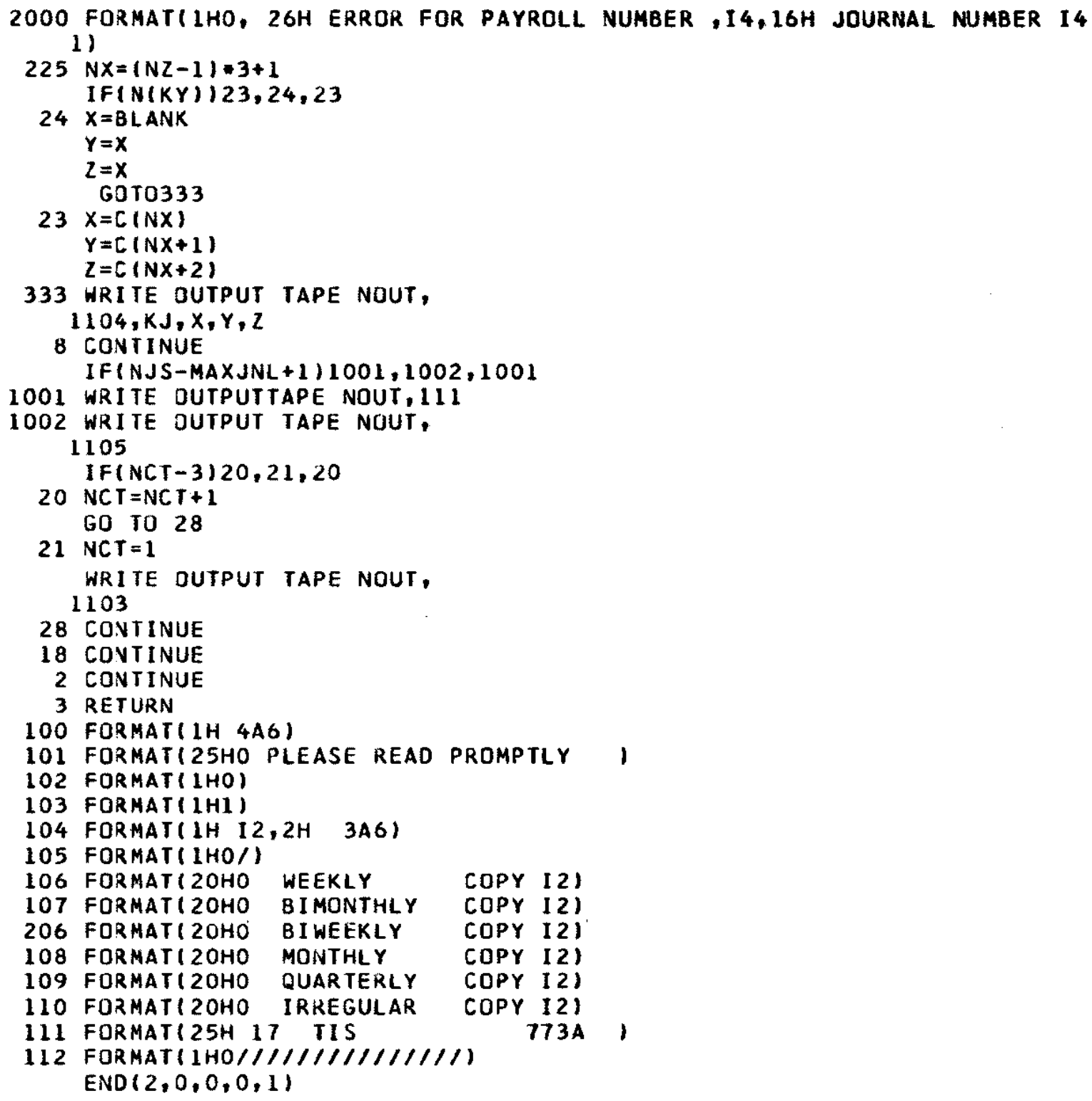


C PURPOSE TO PROVIDE A LIST OF THOSE JOURNALS WHICH MUST BE

C RE-ORDERED TWO MONTHS HENCE.

DIMENSION A(95),N(500),C(20800),NA(95),NI(16),IX(400),NC(20800)

$1, K P N(1000)$

COMMON C,BLANK, N, A,NI, IX, KPN

COMMON MONTH, NAMNO, MAXPER, MAXJNL, NAMJNL, KIN, LIMM, LIMM2, KINN

EQU IVALENCE (NC $(1), C(1)),(B L A N K, B L A N K),(N(1), N(1)),(N A(1), A(1))$

NIN $=5$

NOUT $=10$

$I V=1$

$M M=M O N T H+2$

I F $(M M-12) 150,150,151$

$151 M M=M M-12$

150 I $Z=1$

REWIND NIN

READ TAPE NIN, $(C(J), J=1, K I N)$

DO $10 \mathrm{KL}=1,5000$

$10 N C(K L)=0$

DO $42 K Z=1, L I M M$

READ TAPE NIN, (AIML), ML $=1,95),(N(M P), M P=1,500)$

IF $(A(1)) 145,145,44$

44 IF(NA(5)-MM) 42,152,42

152 IF(NA(6)) 154,153,154

$154 N C(1 Z)=N A(1)$

$1 Z=1 Z+1$

60 TO 42

153 IF(IV-1)1153,1154,1153

1154 WRITE DUTPUT TAPE NOUT, 103, MM

1153 WRITE DUTPUT TAPE NOUT, $100,(\mathrm{~A}(\mathrm{~J}), \mathrm{J}=29,39)$

WRI TE QUTPUT TAPE NOUT, $101,(A(J), J=13,17)$

WRI TE OUTPUT TAPE NUUT, $101,(A(J), J=18,221$

WRITE OUTPUT TAPE NOUT, $101,(A(J), J=23,28)$

IF (IV-14) 160,161,160

$160 I V=I V+1$

GO TO 42

161 I $V=1$

42 CONTINUE

145 NIN $2=4$

REWIND NIN2

DO $200 \quad L M=1,35$

$K O=(L M-1) * 144+1$

IF (NC(KO) ) $402,403,402$

402 DO $203 K X=1,144$

$K Y=K O+K X-1$

$203 N(K X)=N C(K Y)$

WRI TE TAPE NIN2, (N(KZ),KZ=1,144)

200 CONTINUE

$403 N(1)=0$

WRITE TAPE NIN2, (N(KZ),KZ=1,144)

REWIND NIN2

READ TAPE NIN, $(C(J), J=1, L I M M 2)$

REWIND NIN

DO $20 \mathrm{MN}=1,35$

READ TAPE NIN2, $(N(K Z), K Z=1,144)$

IF $N(1)) 210,13,210$ 


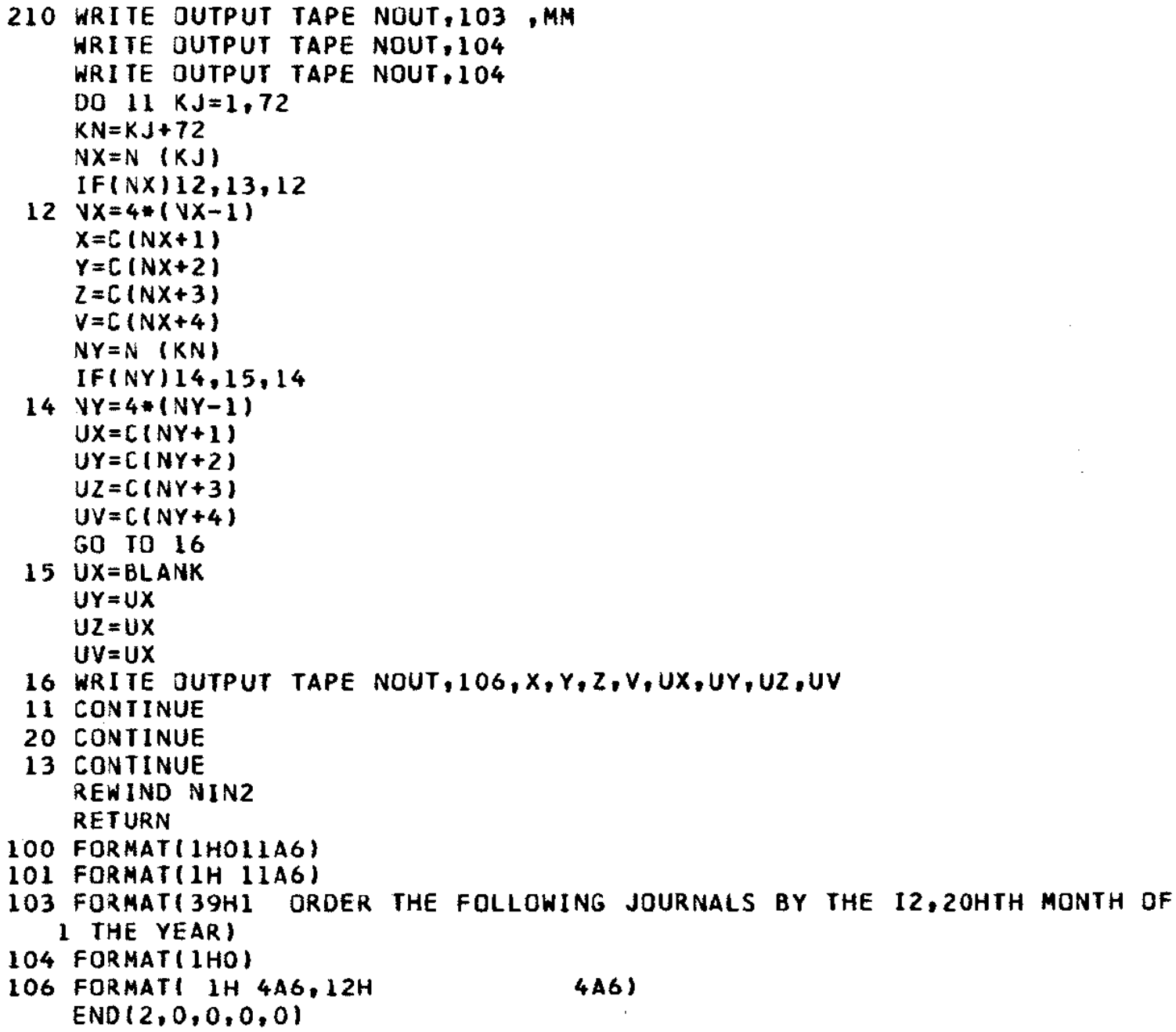




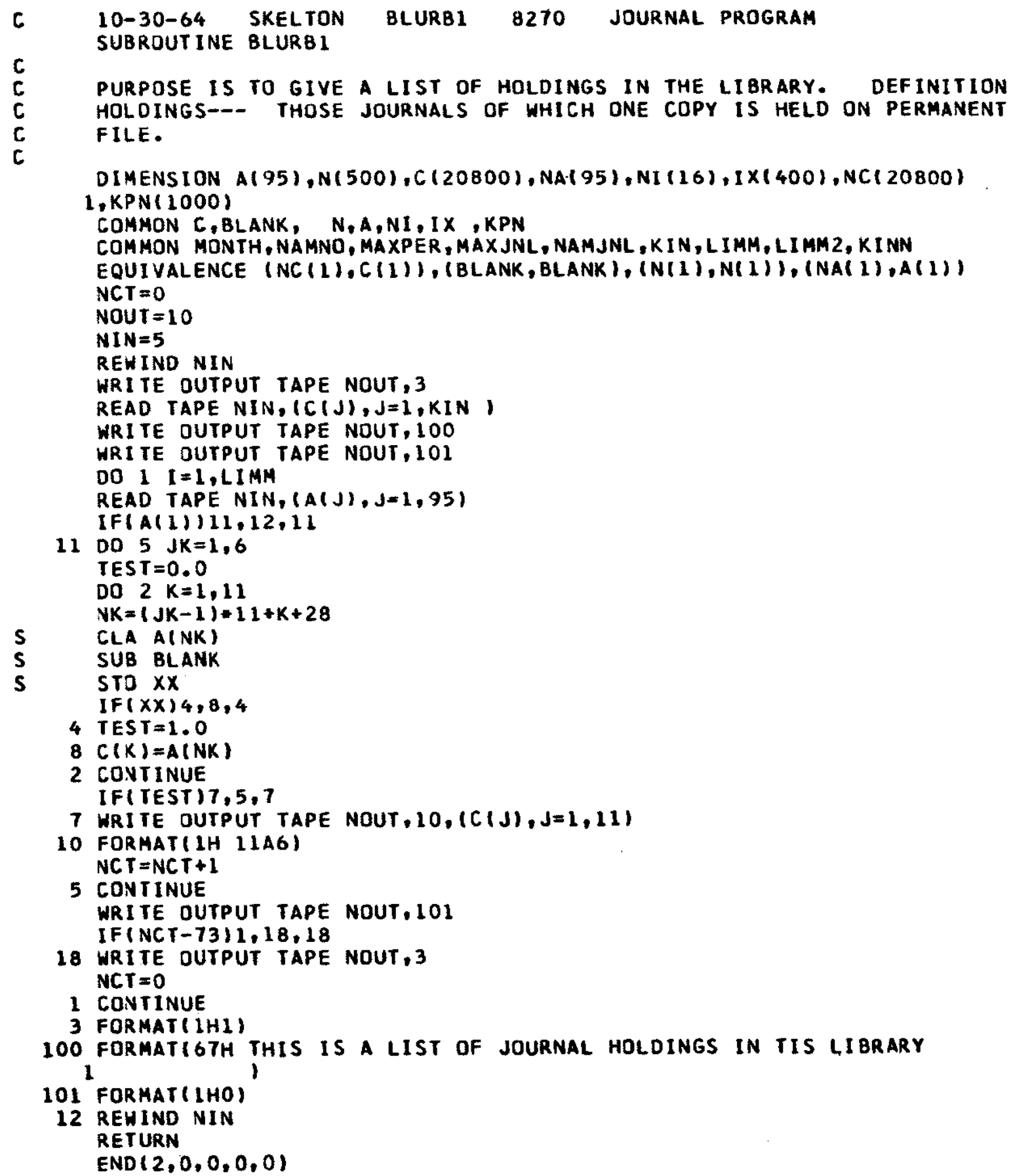

